Revue d'histoire de l'Amérique française

REVUE D.HISTOIRE DE L'AMÉRIQUE FRANÇAISE

\title{
Lionel Groulx — bibliographie (1964-1979)
}

\section{Juliette Rémillard}

Volume 32, numéro 3, décembre 1978

Lionel Groulx, $100^{\mathrm{e}}$ anniversaire de sa naissance, 1878-1978

URI : https://id.erudit.org/iderudit/303723ar

DOI : https://doi.org/10.7202/303723ar

Aller au sommaire du numéro

Éditeur(s)

Institut d'histoire de l'Amérique française

ISSN

0035-2357 (imprimé)

1492-1383 (numérique)

Découvrir la revue

Citer ce document

Rémillard, J. (1978). Lionel Groulx — bibliographie (1964-1979). Revue d'histoire de l'Amérique française, 32(3), 465-523. https://doi.org/10.7202/303723ar d'utilisation que vous pouvez consulter en ligne.

https://apropos.erudit.org/fr/usagers/politique-dutilisation/ 


\section{LIONEL GROULX \\ BIBLIOGRAPHIE \\ (1964-1979)}

Cette bibliographie fait suite à L'Oeuvre du chanoine Lionel Groulx. Témoignages - bio-bibliographie que nous avons publiée en 1964, avec la collaboration de Madeleine Dionne, sous les auspices de l'Académie canadienne-française. Elle comprend les oeuvres $\underline{d e}$ Groulx et les oeuvres sur Groulx de 1964 à 19\%9, sauf pour les enregistrements et les disques dont nous avons fait l'inventaire depuis 1955.

Nous nous en sommes tenue au fonds d'archives de la Fondation Lionel-Groulx déjà très considérable. Nous ne prétendons pas, il va sans dire, faire oeuvre exhaustive. Certaines pièces ont pu échapper à notre attention. Nous espérons tout de même que cette bibliographie rendra service aux chercheurs qui sont toujours les bienvenus pour consulter documents et archives, sur place, à notre Centre de recherche LionelGroulx, au 261 avenue Bloomfield, Outremont.

JULIETTE RÉMILLARD

\section{PLAN}

\section{Oeuvres $\underline{\text { de Groulx }}$}

1. ouvrages

2. rééditions

3. articles

4. préfaces

5. comptes rendus d'ouvrages

6. discours et conférences

7. entrevues.(radio - télévision - presse)

8. enregistrements (rubans magnétiques, disques)

\section{Oeuvres sur Groulx}
1. ouvrages
2. thèses
3. études
4. articles de revues
5. articles de journaux signés
6. articles de journaux anonymes
7. films
8. conférences et allocutions

RHAF, vol. 32, no 3, décembre 1978. 


\section{$-I-$ \\ OEUVRES DE GROULX}

\section{OUVRAGES}

1966 - LA GRANDE DAME DE NOTRE HISTOIRE - Esquisse pour un portrait [ Marie de l'Incarnation] Montréal: Fides, 1966 (Presses des Éditions Fides). $-61 \mathrm{p} . ; 19 \mathrm{~cm} \mathrm{x} 14 \mathrm{~cm}$.

1967 - CHEMINS DE L'AVENIR, Montréal : Fides, 1967 (Presses des Éditions Fides). -161 p. ; $20.5 \mathrm{~cm} \times 14 \mathrm{~cm}$. (Collection Bibliothèque économique et sociale).

- CONSTANTES DE VIE, Montréal; Fides, 1967. (Presses des Éditions Fides). - 174 p.; $15 \mathrm{~cm} \times 20 \mathrm{~cm}$. Préface de Jean Éthier-Blais (Collection Bibliothèque économique et sociale).

1970 - ROLAND-MICHEL BARRIN DE LA GALISSONIÈRE, Québec : Les Presses de l'Université Laval, 1970. - 102 p.; $20 \mathrm{~cm} \mathrm{x} 14 \mathrm{~cm}$. Préface d'André Vachon (Collection Études biographiques canadiennes).

- ROLAND-MICHEL BARRIN DE LA GALISSONIĖRE, Toronto: University of Toronto Press, 1970. - 104 p.; $21 \mathrm{~cm} \mathrm{x} 15 \mathrm{~cm}$. Préface d'André Vachon (Collection Canadian biographical studies).

- MES MÉMOIRES - 1878-1920 - Tome I, Montréal:

Fides, 1970. - (Presses Elite). - 438 p.; $14 \mathrm{~cm} \mathrm{x} 21.5 \mathrm{~cm}$.

1971 - MES MÉMOIRES - 1920-1928 - Tome II, Montréal:

Fides, 1971. - (Presse Elite). - 418 p. $; 14 \mathrm{~cm} \mathrm{x} 21.5 \mathrm{~cm}$.

1972 - MES MÉMOIRES - 1926-1939 - Tome III, Montréal :

Fides, 1972. - (Presses Elite). - $412 \mathrm{p}$.; $14 \mathrm{~cm} \times 21.5 \mathrm{~cm}$.

1974 - MES MÉMOIRES - 1940-1967 - Tome IV, Montréal :

Fides, 1974. - (Presses Elite). -464 p.; $14 \mathrm{~cm} \times 21.5 \mathrm{~cm}$.

\section{RÉÉDITIONS}

1966 - LA DÉCOUVERTE DU CANADA - JACQUES CARTIER (1934) (Collection Fleur de Lys). Montréal: Fides, 1966. - 193 p.

1976 - NOTRE GRANDE AVENTURE - Collection Fleur de Lys (1958). (Collection bibliothèque canadienne-française - "Histoire et documents" (livre de poche). Montréal: Fides, 1976. (Presses Elite). 299 p.; $12 \mathrm{~cm} \mathrm{x} 17.5 \mathrm{~cm}$.

- L'APPEL DE LA RACE (1922); 5e édition, Collection du Nénuphar (1956) - préface de Bruno Lafleur; Montréal: Fides, 1976 (Presses Elite). -252 p.; $14.5 \mathrm{~cm} \mathrm{x} 21.5 \mathrm{~cm}$.

- HISTOIRE DU CANADA FRANÇAIS DEPUIS LA DÉCOUVERTE, I-II-III-IV, L'Action Nationale (1950-1952) - Collection Fleur de Lys en 2 volumes, 1960; Bibliothèque canadienne-française - " Histoire et documents" (livre de poche). Montréal: Fides, 1976. Tome I, 394 p.; Tome II, 443 p.; $12.5 \mathrm{~cm} \times 17.5 \mathrm{~cm}$. 
1977 - LENDEMAINS DE CONQUETTE (1920) - Collection 10/10 (livre de poche). Montréal: Éditions Alain Stanké, 1977 (Presses de Payette et Simms Inc.) -299 p.: $11 \mathrm{~cm} \mathrm{x} 18.5 \mathrm{~cm}$.

- NOTRE MAITTRE LE PASSÉ - Tome 1 - (1924) - Collection 10/10 (livre de poche). Montréal: Editions Alain Stanké, 1977 (Presses de Payette et Simms Inc.) - 321 p.; $11 \mathrm{~cm} \mathrm{x} 18.5 \mathrm{~cm}$.

- NOTRE MAÎTRE LE PASSÉ - Tome II - (1936) - Collection 10/10 (livre de poche). Montréal: Éditions Alain Stanké, 1977 (Presses de Payette et Simms Inc.) -305 p.; $11 \mathrm{~cm} \mathrm{x} 18.5 \mathrm{~cm}$.

- NOTRE MAÎTRE LE PASSÉ - Tome III - (1944) - Collection 10/10 (livre de poche). Montréal: Éditions Alain Stanké, 1977 (Presses de Payette et Simms Inc.) -318 p.; $11 \mathrm{~cm} \mathrm{x} 18.5 \mathrm{~cm}$.

1978 - LA CONFÉDÉRATION CANADIENNE - Ses origines (1918) Collection 10/10 (livre de poche). Montréal: Éditions Alain Stanké, 1978 (Presses de Payette et Simms Inc.) -264 p.; $11 \mathrm{~cm} \times 18.5 \mathrm{~cm}$.

- LES RAPAILLAGES (1916) - Préface de Jean Éthier-Blais. Montréal: Leméac, 1978 (Presses des Ateliers Marquis, Montmagny) - 149 p.; 15 $\mathrm{cm} \times 23 \mathrm{~cm}$.

\section{ARTICLES}

1957 - «La France a-t-elle perdu ou abandonné le Canada ", dans Cahiers de l'Académie canadienne-française, 2-Histoire, 9-22.

1964 - «Dollard Des Ormeaux", dans Cahiers de l'Académie canadiennefrançaise, 8-Ville-Marie, "Poème de la Nouvelle-France", 107-113.

- "Louis-Hector de Callières", dans Cahiers de l'Académie canadiennefrançaise, 8-Ville-Marie, "Poème de la Nouvelle-France", 123-130.

- «Lettre ouverte au Colonel Sarto Marchand", Le Laissez-Passer canadien-français (février).

- «In memoriam", Mgr J.-M. Phaneuf, p.d., L'Écho de Bourget (février).

- "L'inventaire des besoins de nos institutions", Le Laissez-Passer canadienfrançais (avril).

— «Choix du bassin laurentien ", 172-174; «Le coureur de bois », 175-181; "Le canot ", 182-183; "Une épopée dans le bronze », 192; biog. et portrait, 481-482, dans Lectures littéraires, tome III, Les Frères de l'Instruction chrétienne, La Prairie, 1964.

- "L'habitat canadien", 253-258; "Les Canadiens français aujourd'hui", $259-263$; «Un monde était leur empire ", 599 ; biog. et portrait, 260, 827828 , ibid., s.d., IV.

1964-Chronique de l'Institut, RHAF, 17,4 (mars 1964): 612-614; 18,1 (juin 1967- 1964) : 162-164: 18,2 (sept. 1964) : 316-318; 18,3 (déc. 1964) : 474-476; 18,4 (mars 1965) : 628-631; 19,1 (juin 1965): 160-162;19,2 (sept. 1965) : $332 ; 19,3$ (déc. 1965) : 500-501; 19,4 (mars 1966) : 665-666; 20,1 (juin 1966) : 167-169; 20,2 (sept. 1966) : 342-343; 20,3 (déc. 1966) : 522-524; 20,4 (mars 1967) : 701-704. 
1965 - «Notre avenir politique », extraits parus dans Le Droit, Ottawa, 27 janvier et 28 janvier.

— "En cette veille 1965 ", Le Message des Fondateurs de l’Église du Canada, 4,1 (janvier): 1 .

- «Opinion du chanoine Groulx sur les États associés", L'Information nationale (février): 6 .

— «Lettre à Idéal féminin" - revue - (mars).

- "Paul Guillet, le patriote de Rosemont». Le Devoir, 15 novembre.

- "Lettre ouverte à Jean Lesage ", pseudonyme Isidore Legrobeur, L'Action nationale, 54, 9 (mai 1965) : 924-927.

— «Lettre au président général de la SSJB, M. Yvon Groulx - «Faut-il décréter l'unilinguisme par une loi?", L'Information nationale, novembre.

1966 - «Un Québec fort », Les agendas patriotiques incorporés (Québec).

— "Priorité du français dans le Québec", Revue du Bon Parler français.

- "Présentation" de genèse d'une étude graphologique sur Marguerite Bourgeoy's, RHAF, 20,1 (juin 1966): 77.

- Extrait de Directives: "Survivance-2", dans Québec : hier et aujourd'hui, anthologie éditée par Laurier LaPierre, MacMillan Limited, 1966.

— «Le père 'Papin' et l'Action française", In memoriam, 12 octobre. paru dans Relations (novembre 1966) : 296-297.

1967 - Lettre de Lionel Groulx, à Aujourd'hui Québec, 3,1 (mars).

- Léo-Paul Desrosiers, "Âme de qualité-noble esprit, In Memoriam ", Le Devoir, 22 avril.

- "Pierre de la Gorce", dans Cahiers de l'Académie canadienne-française, 11-Reconnaissances Ittéraires, 130-136.

— «Ce cinquantenaire» (extrait de l'Action française) juillet 1917, no 7 : 193203), paru dans le no spécial de la RHAF, 21,3a: 667-675.

- "Pour une relève", extraits de Pour bâtir, dans Laurier L. LaPierre, Québec: hier et aujourd'hui, The MacMillan Company Limited, 1967. 268-270.

- «Les Canadiens français et l'établissement de la Confédération" (extrait de : Les Canadiens français et la Confédération canadienne (enquête de l'Action française, Bibliothèque de l'Action française, 1927, 1-21) paru dans le numéro spécial de la RHAF, 21,3a: 679-694.

1968 - «Le coureur de bois" - extrait de Notre grande aventure, dans Cours de français. Exercices de grammaire et textes d'application, par Jean-Pierre Laferrière et André Benoit. Les Éditions françaises, Montréal, 171-173.

1969 - «Le nationalisme », RHAF, 22,4 (mars 1969) : 524-616; en particulier, 563$566,582,586$.

- «Le problème économique - synthèse", article paru dans L'Action française (1921); reproduit dans Roger-J. Bédard, L'Essor économique du Québec, Montréal, Beauchemin, 50-62.

— «Faut-il décréter l'unilinguisme par une loi?", lettre de Lionel Groulx à Me Yvon Groulx. Reproduite dans L'Information nationale, mars. 
1970 - «L'herbe écartante - ce que racontait grand'mère" - extrait des Rapaillages, paru dans Le français vivant - lectures choisies - 2e livre, par Jean-Pierre Laferrière et Jean-Claude Corbeil. Montréal, Les Éditions françaises Inc., 170-178.

- «Ce vague patriotisme sans substance" - Message aux délégués de l'assemblée préliminaire des États généraux du Canada français, sept. 1966. Reproduit dans l'Écho de Vaudreuil-Soulanges, 18 juin.

1972 - «Le problème économique ", extrait de Notre problème économique Enquête de l'Action française, reproduit dans $C H O C$, avril.

1974 - «Sur une femme au courage d'homme... (sa mère)", reproduit dans Le Devoir, septembre.

1978 - «L'engagement chrétien " — «L'historien et l'amour de son pays » — deux textes reproduits dans L'Église de Montréal, 20 (18 mai) : 323 ; reproduit dans l'Osservatore Romano (27 juin) : 10.

\section{PRÉFACES}

1964 - Mercier, Jean, ptre, L'Estrie. Apotolat de la Presse, Sherbrooke, 1964, 1 p. 1965 - Daveluy, Marie-Claire, La Société de Notre-Dame de Montréal, 16391663, Fides, Montréal, 1965. 1 p.

1967 - Ménard, Jean, Xavier Marmier et le Canada. Les Presses de l'Université Laval, Québec 1967. vii-ix p.

1967 - Hare, John et Jean-Pierre Wallot, Les imprimés dans le Bas-Canada 18011840 - bibliographie analytique, Les Presses de l'Université de Montréal, 1967, vii-viiip.

1967 - Martin, Serge, Montréal et son histoire - Diapositives 24 x 36 en couleurs Haute Fidélité. Textes de Serge Martin / photographies de Paul Carignan. Coll. Histoire et civilisations. Secas internationale, Montréal et Paris (1967), 1 p.

\section{COMPTES RENDUS D'OUVRAGES}

«À travers quelques revues ", RHAF, 19,4 (mars 1966) : 645.

Aubert de la Rue, Philippe, Canada incertain, RHAF, 20,2 (sept. 1966) : 316 319.

Audet, Louis-Philippe, Histoire du Conseil de l'Instruction publique, RHAF, 18,1 (juin 1964) : 155-160.

Beers, Henry Putney, The French and British in the Old Northw'est, R HAF, 18,2 (sept. 1964) : 295-297.

Bergevin, André, Cameron Nish, Anne Bourassa, Henri Bourassa, RHAF, 20,4 (mars 1967): 639-641.

Bibliographie annuelle de l'histoire de France, RHAF, 17,4 (mars 1964): 588 ; 18,3 (déc. 1964): 447-448; 19,2 (sept. 1965): 320.

Brazao, Eduardo, La découverte de Terre-Neuve, RHAF, 18,2 (sept. 1964): 304-305.

Brien, Roger, "Lettre de Lionel Groulx à propos de Prométhée", Le Nouvelliste, Trois-Rivières, 24 septembre 1966. 
Brochu, Michel, Suggestions pour un réaménagement de l'administration du Nouveau-Québec; "Présentations et commentaires de cartes sur le NouveauQuébec"; "Toponymie des côtes du Nouveau-Québec", RHAF, 19,4 (mars 1966): 647-648.

Bulletin de la Société franco-américaine, XI (1965), RHAF, 20,4 (mars 1967): 664-665.

Bulletin de liaison de la Société des professeurs d'histoire, RHAF, 19,4 (mars 1966) : 645-647.

The Catholic Historical Review - 50th Anniversary, RHAF, 19,2 (sept. 1965) : 320-322.

Catta, Étienne, Le frère André (1845-1937) et l'Oratoire St-Joseph du MontRoval, RHAF, 19,1 (juin 1965): 142-144.

Charland, Thomas-M., o.p., Histoire des Abénakis d'Odanak (1675-1937), RHAF, 18,1 (juin 1964): 153-155. - Reproduit dans Québec 65 (fév. 1965): 112-113.

Clément, Béatrice, Marie de la Ferre 1592-1652, RHAF, 18,2 (sept. 1964) : 301302.

Dagenais, André, Vingt-quatre défauts thomistes, RHAF, 18,2 (sept. 1964): 309-312; paru dans Le Devoir, 7 novembre 1964.

Daveluy, Marie-Claire, La Société de Notre-Dame de Montréal, 1639-1663, RHAF, 19,2 (sept. 1965) : 322.

Debien, Gabriel, "Les origines des esclaves des Antilles ", tomes XXIV et XXV, Bulletin de l'IFAN, RHAF, 18,4 (mars 1965): 622-623.

De la Morandière, Charles, Histoire de la pêche de la morue dans l'Amérique septentrionale, RHAF, 19,4 (mars 1966): 643-645.

Desrosiers, Léo-Paul, Dans le nid d'aiglons, la Colombe - Vie de Jeanne Le Ber, la recluse, R H AF, 17,4 (mars 1964): 583-586.

De Ville, Winston, Marriage Contracts of Natchitoches, 1739-1803, RHAF, 17,4 (mars 1964) : 587-588.

De Volpi, Charles et P.S., Winkworth, Montréal, RHAF, 18,3 (déc. 1964) : 462.

Dictionnaire biographique du Canada, Volume I, de l'an 1000 à 1700, RHAF, 19,4 (mars 1966): 637-640.

Dionne, Gérard, La situation de l'Église en Amérique latine, R HAF, 20,2 (sept. 1966) : 315-316.

Douville, Raymond et Jacques-Donat Casanova, La vie quotidienne en Nouvelle-France - Le Canada, de Champlain à Montcalm, RHAF, 18,2 (sept. 1964) : 297-299. - Reproduit dans Québec 65 (février 1965) : 110-112.

Fohlen, Claude, L'Amérique anglo-saxonne de 1815 à nos jours, RHAF, 19,1 (juin 1965): 141-142.

Fontaine, Marie-Blanche, Une femme face à la Confédération, RHAF, 19,1 (juin 1965): 139-141.

Galarneau, Joffre, René Bazin et le problème social, RHAF, 20,2 (sept. 1966): 312-314.

Gervais, Émile, S.J., Les Six - Les Fondateurs de l'Église du Canada, RHAF, 19,2 (sept. 1965) : 317-319.

Histoire du Canada, "Mes fiches", RHAF, 18,1 (juin 1964): 150-151. 
Jacquemyns, G., Langrand-Dumonceau, RHAF, 18, I (juin 1964) : 146-147. Lacroix, Benoît, o.p., Le Japon entrevu, RHAF, 20,1 (juin 1966) : 132-134.

"Lamennais au Canada français", L'Entraide fraternelle, RHAF, 18,3 (déc. 1964) : 461-462.

Lamontagne, Roland, Succès d'intendance de Talon, RHAF, 18, 1 (juin 1964) : 151-153.

Lamontagne, Roland, La vie et l'oeuvre de Pierre Bouguer, RHAF, 18,3 (déc. 1964) : 445-447.

Lamontagne, Roland, Aperçu structural du Canada au XVIIIe siècle, RHAF, 19,1 (juin 1965) : 136-139.

Lamontagne, Roland, L'Administration du Canada, RHAF, 19,4 (mars 1966) : 641-642.

Lamontagne, Roland, L'Atlantique jusqu'au temps de Maurepas, RHAF, 19,4 (mars 1966) : 642-643.

Lamontagne, Roland, Ministère de la marine, Amérique et Canada, RHAF, 20,2 (sept. 1966) : 320-321.

LeBlant, Robert, La condition sociale de Samuel Champlain, RHAF, 18,2 (sept. 1964) : 299-300.

Le Gardeur, René-J., The First New Orleans Theatre 1792-1803, RHAF, 18,2 (sept. 1964) : 299.

Lemieux, Germain, S.J., Chanteurs franco-ontariens et leurs chansons, R HAF, 19,2 (sept. 1965) : 319-320.

Maheux, Mgr Arthur, m.s.r.c., P.-J.-O. Chauveau, promoteur des sciences, RHAF, 18,3 (déc. 1964) : 458-460.

Martel, Jules, Les troubles de 1837-38 dans la région de Sherbrooke, RHAF, 17,4 (mars 1964) : 603.

Massignon, Geneviève, "Les noms de famille en Acadie", Revue internationale d'Onomastique, RHAF, 18,4 (mars 1965): 623.

McDermott, John Francis, The French in the Mississipi Vallev, RHAF, 19,2 (sept. 1965) : 314-315.

Mercier, Jean, L'Estrie, RHAF, 19,2 (sept. 1965) : 315.

Mercier, Jean, Autour de Mena'Sen, RHAF, 19,2 (sept. 1965) : 316-317.

Mitchell, E.,. Messire Pierre Boucher, RHAF, 21,1 (juin 1967): 132-133.

Mitchell, Soeur Estelle, Mère Jane Slocombe, neuvième supérieure générale des Soeurs Grises de Montréal, 1819-1872, RHAF, 18,3 (déc. 1964): 443-445.

Morin, Rosaire, Réalités et perspectives économiques, RHAF, 21,1 (juin 1967): 133-134.

Montréal 1964, RHAF, 18,3 (déc. 1964) : 462.

Montréal - l'Age d'or - The Golden Years, RHAF, 20,1 (juin 1966) : 131.

Morton, W.L., The Kingdom of Canada, RHAF, 17,4 (mars 1964) : 573-580.

O'Neill, Charles Edwards, Church and State in French Colonial Louisiana Policy and Politics to 1732, RHAF, 20,4 (mars 1967): 646-649.

Parizeau, Gérard, Bas-Canada - I800 : le milieu et ses problèmes, R HAF, 18,3 (déc. 1964) : 460-461.

Prince-Falmagne, Thérèse, Un marquis du grand siècle - Jacques René de Brisay de Denonville, gouverneur de la Nouvelle-France 1637-1710, RHAF, 19,3 (déc. 1965) : 477-481. 
Provost, l'abbé Honorius, Le Séminaire de Québec, RHAF, 20,1 (juin 1966): 131-132.

Rapport Parent, RHAF, 20,3 (déc. 1966): 458-466. Paru dans l'Action nationale, LVI (mai 1967) : 843-854. Reproduit dans Le Droit, 27 mai 1967.

Roquebrune, Robert de, Quartier Saint-Louis, RHAF, 20,3 (déc. 1966) : 504505.

Ryan, William F., The Clergy and Economic Growth in Quebec 1897-1914, RHAF, 20,4 (mars 1967): 641-646. Reproduit dans Le Devoir, 12 mai 1967.

Séguin, Robert-Lionel, Les granges du Québec du XVIIe au XIXe siècle, RHAF, 18,3 (déc. 1964) : 448-449.

Skelton, R.A., et als, The Vinland Map and the Tartar Relation, RHAF, 19,3 (déc. 1965): 481-484.

Société historique de Boucherville, Histoire véritable et naturelle ... 1664 Pierre Boucher, RHAF, 18,4 (mars 1965) : 604-606.

Soeur Thérèse du Carmel, s.s.j., Bibliographie analytique de l'oeuvre de FélixAntoine Savard, RHAF, 21,1 (juin 1967): 145-146.

Traversy, Léo, La paroisse de St-Damase, Comté de Saint-Hyacinthe, RHAF, 19,4 (mars 1966) : 637.

Vaugeois, Denis, La civilisation française et catholique au Canada, R HAF, 20,4 (mars 1967): 565.

Watelet, H., Notes sur le classement d'archives d'entreprises familiales, RHAF, 19,2 (sept. 1965) : 317.

Wyczynski, Paul, dir., François-Xavier Garneau - Aspects littéraires de son oeuvre, RHAF, 20, 1 (juin 1966) : 134-137.

\section{DISCOURS ET CONFÉRENCES DE LIONEL GROULX}

1964 - Au Monument LaFontaine, au Parc Lafontaine, Montréal, le 26 février.

- Conclusions d'une rencontre "religieux et hommes d'affaires", tenue au Collège Saint-Paul, le 11 avril.

- Au banquet de l'IHAF, 25 avril.

- À la bénédiction de l'immeuble Fides, 20 mai.

- À la Fédération des Sociétés Saint-Jean-Baptiste du Québec, au Château Frontenac, 7 juin.

-À Vaudreuil, conférence à la Société Saint-Jean-Baptiste, 29 novembre.

- Allocution au lancement de Chemins de l'avenir, 21 décembre.

1965 - Au Monument National, 10 janvier, à la réception du Nouvel an. Allusion au rapport Parent.

- Lancement littéraire, à Boucherville, 25 janvier.

- Banquet de l'Action Nationale - remerciements au conférencier FrançoisAlbert Angers, 25 avril.

- À la réunion générale de l'IHAF, ler mai.

- Allocution devant un groupe d'étudiants franco-albertains, à la SSJB de Montréal, 12-13-14 juillet.

- Allocution au Congrès de l'Ordre de Jean-Talon, à Québec, 25-26 septembre. 
— «Ma conception de l'histoire ", à l'Université de Montréal, 24 novembre, commémoration du cinquantenaire du ler cours d'histoire du Canada.

1966 - «Urgence d'un enseignement fervent de l'histoire du Canada français ", à la réunion de l'IHAF, 30 avril.

- Message comme président d'honneur des États généraux, 25-27 novembre.

1967 - Rencontre et discussions - «Pourquoi les hommes réécrivent-ils leur histoire à chaque génération ", 7 mai, au Pavillon de la Jeunesse, Terre de l'Expo 67.

\section{ENTREVUES (RADIO-TÉLÉVISION-PRESSE)}

1964-- René Viau, ptre, "Le térésien de l'année - visite chez un illustre ancien ", Les Annales térésiennes, février 1964, LI, 2.

- 15 minutes d'entretien avec Renée LaRochelle sur La Fontaine, 26 février 1964, à la radio CBF.

- Conrad Langlois, "Les revendications du chanoine Lionel Groulx se réalisent après 40 ans - entrevue ", La Patrie, 26 mars-1er avril 1964.

- Entrevue, The Star Weekly and Canadian Weekly, 4 avril 1964.

- À l'émission Aujourd'hui, Radio Canada télévision, entrevue avec PaulÉmile Tremblay, sur le nationalisme, 15 avril 1964.

— Julia Richer, "Je n’ai jamais été qu'un écrivain engagé », Cahier littéraire, lors de l'inauguration de l'immeuble Fides, 20 mai 1964.

- À l'émission Aujourd'hui, Radio Canada télévision, entrevue avec PaulÉmile Tremblay, sur Chemins de l'Avenir, le 22 décembre 1964.

1965 - Pierre Léger, Deux heures avec le chanoine Lionel Groulx: "Notre jeunesse se détruit... j'ai peur pour notre avenir." Photo-Journal, semaine du 6-13 janvier 1965, 4.

- «Le Dr Jutras reçu par notre historien national, le chanoine Groulx », La Nouvelle, Victoriaville, 19 janvier 1965.

- Entrevue avec le Frère Untel, sur Chemins de l'avenir, à Radio-Canada, télévision, 27 janvier 1965.

- Pierre Dionne, pour la revue Servir des Scouts canadiens-français : " 60 minutes avec le chanoine Groulx ", 22 (mars-avril 1965); Opinions 65, 2 (mars 1965); Le Brasier, 27, 1 (août-sept.-oct. 1967).

- Hal Winter, "Relentless in his beliefs ", The Montreal Star, 23 janvier 1965.

- À l'émission Aujourd'hui, Radio-Canada télévision, 24 novembre 1965.

1966 - Hubert Gendron, "A Chat with Canon Lionel Groulx, 88 Tomorrow ; « My work is finished but Success is sight ", The Gazette, 12 janvier 1966, 37.

- À l'émission dominicale, Radio-Canada télévision, entrevue avec l'abbé Gérard Lalonde, 19 mai 1966. 28 minutes.

1967 - Programme "Votre choix », Nicole Germain et Lise Payette reçoivent le chanoine Lionel Groulx, Radio-Canada, 17 janvier.

- Louis Martin, "L'histoire comme ils l'ont faite", à Radio-Canada, 28 janvier 1967.

- Radio-Canada, "L'histoire comme ils l'ont faite", consacrée à Lionel Groulx, le 25 février 1967. 30 minutes. 
- Radio-Canada, "L'histoire comme ils l'ont faite", consacrée à Henri Bourassa, participation de Lionel Groulx, le ler avril 1967.

- Marie-Lise Brunel, interview du 25 mars 1967 - 2 heures.

- Gilles Gariépy. "La Revue d'histoire témoigne depuis vingt ans", Le Devoir, 15 avril 1967.

\section{ENREGISTREMENTS :}

a) rubans magnétiques

1955 - Message de Lionel Groulx à ses compatriotes de l'Ouest, 21 juillet.

1956 - Entrevue avec René Lévesque: L'APPEL DE LA RACE (réédition) et RENCONTRES AVEC DIEU. Souvenirs sur Armand LaVergne par Lionel Groulx (sur même bobine).

1958 - Conférence de presse sur la Confédération avec André Laurendeau, à l'émission «Pays et Merveilles", Radio-Canada, Canal 2, 2 juillet.

- Jugements du Chanoine sur Omer Héroux et Dr Joseph Gauvreau, (extraits de ses Mémoires), 23 août.

- Conversation avec M. Paul Guillet: patriotisme, etc.

1959 - Entrevue de Lionel Groulx sur Mère d'Youville, avec Guy Viau, CBFT, 14 mai.

- Ma conception de l'histoire à Radio-Canada, à l'émission "Conférence " (T.V.), 22 décembre. Texte complet paru dans l'ACTION NATIONALE (avril 1960): 603-617.

1960 - Entrevues sur les missions canadiennes, à Radio-Canada T.V., canal 2, ler et 8 mai (avec le Père Régis).

1961 - Bienvenue à la famille, 13 janvier.

1962 - Discours sur le "séparatisme" à la Société Saint-Jean-Baptiste de Vaudreuil, 25 février.

- Réflexions de Lionel Groulx avant et au retour d'un voyage à Vaudreuil à la fin de l'hiver. Fables de LaFontaine dites par Lionel Groulx (s.d.).

1963 - Sermon du chanoine au 25e anniversaire de sacerdoce de Lucien Léger, ptre, à Saint-Zotique, 28 juillet.

1965 - Petit discours fourni aux auditeurs de l'Ordre de Jean-Talon, (réunion du 25-26 septembre).

- Souvenirs du chanoine Lionel Groulx sur «Ma Mère" (s.d.).

- «Rencontre", avec les étudiants en histoire de l'Université de Montréal, à l'occasion du 50e anniversaire du premier cours d'histoire du Canada de Lionel Groulx. Sciences de l'éducation, UM.

1967 - Entrevue avec Marie-Lise Brunel, sur le nationalisme. Archives de l'Université de Montréal, audiovidéothèque, Sciences de l'éducation.

- L'histoire comme ils l'ont faite, à Radio-Canada, 25 février.

1978 - Le chanoine Lionel Groulx, émission "Sous le chêne de Mambré ", à Radio-Canada, 29 janvier 1978 (sur cassette).

b) disques

1942 - Henri Bourassa, discours de novembre 1942 dans le comté d'Outremont. Face 6, présentation et commentaires du chanoine Lionel Groulx. 
1944 - Conférence d'Henri Bourassa, à la salle du Plateau, 2 février 1944 ; face 1 présentation de Lionel Groulx; face 5 - commentaires de Lionel Groulx, novembre 1942; face 6-introduction de Lionel Groulx; face 7 - liaisons explicatives; face 8 - liaisons explicatives.

1949 - Disques des 100 cours d'histoire du Canada donnés à la radio, poste CKAC, à partir du 4 décembre 1949, à raison d'un cours par semaine.

1950 - Entrevue du chanoine Lionel Groulx avec Raymond Laplante, émission "Revue de l'actualité ", à Radio-Canada, 15 mai.

1960 - Manifestation à l'occasion de la présentation en primeur du film «Le chanoine Lionel Groulx, historien ", allocution, 3 février.

1964 - Discours à la Fédération des Sociétés Saint-Jean-Baptiste du Québec, au Château Frontenac, 7 juin 1964.

\section{- II - \\ OEUVRES SUR GROULX}

\section{OUVRAGES}

1964 - Rémillard, Juliette et Madeleine Dionne, L'oeuvre du chanoine Lionel Groulx - Témoignages - Bio-bibliographie. Les publications de l'Académie canadienne-française, Montréal, 1964, 198 p., 26 x $18 \mathrm{~cm}$.

1966 - Stanley, George F.G., «Lionel-Adolphe Groulx : Historian and Prophet of French Canada ". Four o'clock lectures - french-canadian thinkers of the nineteenth and twentieth centuries, Laurier L. LaPierre, éd., 97-114, 117 p. $20 \mathrm{~cm} \times 15 \mathrm{~cm}$.

1967 - Lacroix, Benoît, Lionel Groulx, Textes choisis et présentés, Collection Classiques canadiens, no 30, Montréal et Paris, Fides, 1967, 96 p. 16.5 $\mathrm{cm} \times 11 \mathrm{~cm}$.

1968 - Action Nationale, Lionel Groulx, prêtre, (13 janvier 1878 - 23 mai 1967) l'homme, l'oeuvre, Volume LVII, no 10, Montréal, juin 1968, 831 à 1115 p., $21 \mathrm{~cm} \times 13 \mathrm{~cm}$.

- Roy, Jean-Louis, Maîtres chez nous (Dix années d'Action Française), (1917-1927) Montréal, Leméac, 1968, 78 p. $14 \mathrm{~cm}$ x $21.5 \mathrm{~cm}$.

1970 - Gaboury, Jean-Pierre, Le Nationalisme de Lionel Groulx : aspects idéologiques, "Cahiers des sciences sociales ", 6. Ottawa, Éditions de l'Université d'Ottawa, 1970 , VIII-226 p. $23.5 \mathrm{~cm} \times 15.5 \mathrm{~cm}$.

1973 - Éthier-Blais, Jean, Discours de réception à l'Académie canadiennefrançaise suivi de l'oeuvre de Lionel Groulx d'Olivar Asselin. Collection Renaissance, Montréal, Éditions Hurtubise HMH, 1973, 155 p., $18.5 \mathrm{~cm}$ $\mathrm{x} 11.5 \mathrm{~cm}$.

- Renaud, Laurier, La fondation de l'A.C.J.C. - L'histoire d'une jeunesse nationaliste, Préface de Jean-Paul Simard. Presses collégiales de Jonquière, 1973,154 p. $12.5 \mathrm{~cm} \mathrm{x} 20 \mathrm{~cm}$.

- Mann-Trofimenkoff, Susan, ed., Abbé Groulx - Variations on a nationalist theme. Copp Clark Publishing, Toronto, 1973. «Issues in Canadian History ». $21.5 \mathrm{~cm} \times 13.5 \mathrm{~cm}$. 
1975 - Mann-Trofimenkoff, Susan, "L'Action française : French Nationalism in Quebec in the Twenties, Toronto, University of Toronto Press, 1975, 157 p. $23.5 \mathrm{~cm} \times 15.5 \mathrm{~cm}$.

1978 - Filion, Maurice, dir., Hommage à Lionel Groulx, Leméac, Montréal, 224 p. $19 \mathrm{~cm} \times 21.5 \mathrm{~cm}$.

-Frégault, Guy, Lionel Groulx tel qu'en lui-même, Montréal, Leméac, 1978, 237 p. $15 \mathrm{~cm} \times 22.5 \mathrm{~cm}$.

- Giguère, Georges-Émile, Lionel Groulx - biographie, Montréal, Éditions Bellarmin, 1978, 160 p. $13.5 \mathrm{~cm} \mathrm{x} 21 \mathrm{~cm}$.

\section{THẼSES}

1959 - Jolicour, Louis-Philippe, L'Action française de Montréal 1917-1928, étude suivie d'un index, thèse présentée à la Faculté des Lettres de l'Université de Montréal pour l'obtention du grade de Maîtrise ès Arts, (histoire), Montréal 1959, $171 \mathrm{p}$.

1966 - Périn, René, Le chanoine Groulx et la Conquête : a-t-il modifiéses idées au cours des dernières années? travail présenté à Jacques Mathieu, (histoire 603), au Séminaire Sainte-Marie, 21 avril 1966.

1968 - Moisan, Omer, "Le roman de l'énergie nationale" et "Les bastions de l'Est", de Maurice Barrès et "L'Appel de la race" de Lionel Groulx, (thèse de DES, Université de Montréal, 1968).

1969 - Brunel-Guitton, Marie-Lise, La pensée historique de Lionel Groulx, thèse présentée à la Faculté des Lettres de l'Université de Montréal pour l'obtention du grade de Maîtrise ès Arts (M.A. histoire), Montréal 1969, $194 \mathrm{p}$.

1970 - Mann, Susan Robertson (Trofimenkoff), L'Action française : L'Appel de la race, thèse présentée à l'école des gradués de l'Université Laval pour obtenir le doctorat de l'Université, février 1970, 429 p.

- Renaud, Laurier, La Fondation de l'A.C.J.C., thèse de Maîtrise en histoire présentée à l'Université Laval, 1970, $174 \mathrm{p}$.

1971 - Bélec, Jacques, "Yensée socio-économique de l'A CJC, 1904-1934 », (M.A. Histoire, Université de Montréal, 1971).

- Péloquin, Claude, "Les structures mentales de la pensée de Lionel Groulx" (projet de thèse Ph. D., 1971).

- Villemure, Gilles. "Lionel Groulx et les débuts de l'enseignement de l'histoire du Canada à Montréal (M.A. Histoire, 1971).

1973 - Courtemanche, Anne, Edition critique des "Rapaillages" de Lionel Groulx, Thèse présentée à la Faculté des études supérieures en vue de l'obtention du grade de Maîtrise ès Arts (études françaises), août 1973, $257 \mathrm{p}$.

- Demers, Christiane, "Idée de démocratie chez Lionel Groulx, années 1930 ", (projet de thèse M.A. Université Laval, Québec, 1973).

- Guiho, Joseph, ptre, "Lionel Groulx et la littérature québécoise (projet de thèse, M.A., littérature, Université de Montréal, 1973). 
1974 - Jolicoeur, Danielle Dagenais-Pérusse, La formation et les premiers engagements d'un nationaliste: Lionel Groulx (1878-1915), Mémoire présenté en vue de l'obtention du grade de Maîtrise ès Arts (histoire), au département d'histoire, Faculté des études supérieures de l'Université de Montréal, février 1974, 193 p.

1975 - Sherrin, Phyllis M., The World, the Flesh and the Devil: The Crusade of Lionel Groulx 1878-1967, A dissertation submitted to the Faculty of Graduate Studies in partial fulfilment of the degree of doctor of philosophy, York University, Toronto, september 1975, 436 p.

1976 - Bonvalet, Roland, L'abbé Groulx par lui-même, thèse pour le doctorat du 3e cycle présentée à l'Université de Paris, Sorbonne (lettres et civilisations), 1976, $397 \mathrm{p}$.

- Guiho, Joseph, Lionel Groulx: Choix raisonné de textes critiques. mémoire présenté à la Faculté des études supérieures en vue de l'obtention de la Maîtrise ès Arts (études françaises), Université de Montréal, février 1976, $149 \mathrm{p}$.

- Letendre, Jean, Lionel Groulx, bio-bibliographie 1964-1976. Faculté des études supérieures, École de bibliothéconomie, Université de Montréal, 1976.

- Mearkle, Kristy. Le Canadien français face à sa destinée d'après les "Mémoires" de Lionel Groulx, mémoire présenté à l'Université de Caen, 1976.

1977 - Fleming, John, L'évolution de la critique de "L'Appel de la race" (1922), mémoire présenté à l'école des gradués de l'Université Laval comme exigence partielle de la Maîtrise ès Arts (études française), août 1977, $75 \mathrm{p}$.

\section{3. ÉTUDES}

Anonyme, Anthologie littéraire de l'Amérique francophone, Sherbrooke, Université de Sherbrooke, 1971, 114-118.

- Année nécrologique: «M. le chanoine Lionel Groulx, décédé le 23 mai 1967 à 89 ans ", Almanach du peuple, Beauchemin, 1968: 319.

- Biographie du chanoine et portrait, Almanach du peuple 1978, Beauchemin, Montréal, 1978.

- Le livre québécois, 1764-1972, MAC, Montréal, Voir Groulx.

Arès, Richard, S.J.,; "Jean-Marc Léger et Lionel Groulx ", dans Nos grandes options politiques et constitutionnelles. Les Éditions Bellarmin, 1972, 148149. - autres extraits, 140, 196, 211, 221.

Barbeau, Victor, "Le témoignage d'un profane", 73-76. La face et l'envers essais critiques. Les Publications de l'Académie canadienne-française, Montréal, 1966.

Barbeau, Victor et André Fortier, Dictionnaire bibliographique du Canada français, Académie canadienne-française, Montréal, 1974, 115-116.

Bastien, Hermas, "Lionel Groulx", dans Ces écrivains qui nous habitent. Beauchemin, Montréal, 1969, 169-192. 
Bélanger, André-J., "Lionel Groulx, une mystique québécoise ", dans L'Apolitisme des idéologies québécoises, le grand tournant de 1935-1936. Les Presses de l'Université Laval, Québec 1974, Collection Histoire et Sociologie de la culture, no 7: 191-255.

- "L'Action Nationale et les Jeune-Canada, le nationalisme à capella ", dans ibid. : 257-304.

- "Lionel Groulx face à Cité libre", dans Ruptures et constantes. Quatre idéologies du Québec en éclatement. HMH, Montréal, 1966, 219 p.

Berger, Carl, "Réorientation", dans The Writing of Canadian History Aspects of English Canadian Historical Writing: 1900-1970. Toronto, Oxford University Press, 1976, 43, 181-186, 206.

Bessette, Gérard, Lucien Geslin, Charles Parent, "Chanoine Lionel Groulx (1878-1967), sa vie, son ouvre; conception de l'histoire, l'anxiété de l'historien ; actualités, l'essai et le journalisme, dans L'Histoire de la littérature canadienne-française par les textes. Centre éducatif et culturel Inc., 1968. 704 p. Voir aux pages $62-64,65-66,69,52,56$.

Blain, Maurice, "Le dernier songe de Cassandre", dans Approximation Essai, Collection Constantes, 11, Édition HMH, Montréal, 1967 : 233-236.

Bouthillier, Guy et Jean Meynaud, Document no 54 - «1913 - Naissance d'un groupe de pression linguistique ", dans Le choc des langues au Québec, 17601970. Montréal, 1972, 354-360.

- Document no 72 - «1934 - Il ne suffit pas de parler français, il faut être français ", ibid, 474-479.

- Document no 101 - «1952 - Des hommes en mal d'un destin », ibid., 614-615.

— «Nécessité d'une perspective historique ", ibid., 9, 14-15.

- Document no 51: «1912 - La France mais pas toute la France», ibid., 339-344.

Brunel, Marie-Lise, "Groulx face à l'économique durant les années 1915-1920", dans Économie québécoise (en coll.), Les Presses de l'Université du Québec, Montréal, 1969, 371-393.

Brunet, Berthelot, "Un chercheur honnête homme", 239-243; "Monsieur Lionel Groulx et les sauvages ", 245-249; "Trente arpents, les idées ", 279, 291 ; divers extraits, 30, 35, 36, 56, 81, 109, 111, 112, 113, dans : Histoire de la littérature canadienne-française, suivie de portraits d'écrivains. Éditions HMH, Montréal, 1970.

Chaloult, René, Voir préface, opinion de Lionel Groulx, chapitre André Laurendeau, Daniel Johnson, le drapeau du Québec, dans Mémoires politiques. Éditions du Jour, Montréal, 1969, 14-17, 91, 92, 166, 240, 282, 289.

Chevalier, Willie, "Préface", dans Olivar Asselin toujours vivant de MarcelAimé Gagnon, Presses de l'Université du Québec, 1974, XII-XX.

Cotnam, Jacques, Bibliographie de Lionel Groulx, dans Contemporary Quebec, Macmillan and Stewart, 1973.

Dorge, Lionel, "Introduction à l'étude des Franco-Manitobains", essai historique et bibliographie, Société historique de Saint-Boniface, 1973, (voir Groulx). 
Duhamel, Roger, "Lionel Groulx 1878-1967», Manuel de littérature canadienne-française. Éditions du Renouveau pédagogique incorporé, Montréal, 1967, 85-86, 157-159.

Dumont, Fernand, Jean Hamelin, Fernand Harvey et Jean-Paul Montminy, "Du début du siècle à la crise de 1929: un espace idéologique", dans Idéologies au Canada français 1900-1929. Les Presses de l'Université Laval, Québec 1974, 1-13.

- «Hommage à Groulx", 12 p., dans André Laurendeau, Ces choses qui nous arrivent, chronique des années 1961 à 1966, HMH, 1970.

- «Lionel Groulx : Mes Mémoires Tome II", Livres et auteurs québécois, 1971 : 218-219.

Esquisses du Canada français, Association canadienne des éducateurs de langue française, Montréal, Fides, 1967, 125, 128, 248. Portrait.

Ethier-Blais, Jean, "Abbé Lionel Groulx - Notre maître l'avenir", dans Signets II. Le Cercle du livre de France, 1967, 149-160, 167, 12, 38-39.

- Préface de Constantes de vie, dans Signets III. "La poésie de l'histoire ». Le Cercle du Livre de France, 1973, 121-135; voir aussi 32, 35, 108, 109, 111, 157, 158, 162, 190, 193, 194.

Falardeau, Jean-Charles, "L'essor des sciences sociales au Canada français", Coll. "Arts, vie et science au Canada français", 6, Québec, Ministère des Affaires culturelles, 1964, 65 p.; voir 15, 28, 34, 35, 41, 43.

Fournier, Rodolphe, "L'école-musée de Vaudreuil; la maison natale du chanoine Lionel Groulx; le décès du chanoine Lionel Groulx - Monument au cimetière de Vaudreuil " dans Lieux et monuments historiques du sud de Montréal, Éditions du Richelieu, 1971; voir 120, 134, 188.

Gagnon, Marcel-Aimé, «À propos du livre de J.-C. Harvey, Marcel Faure, 40 ; "À propos de l'article du JOUR qui portait Lionel Groulx à la tête d'un parti politique ", 99;

"À propos de l'enseignement de l'anglais, opinion Harvey et Groulx ", 122, 123,127 ;

"Groulx, écrivain du terroir" - J.-C. Harvey et l'enseignement - Groulx aurait appuyé cette campagne", 145 ;

"À propos de l'Appel de la race de Lionel Groulx " - " Jean-Charles Harvey et le théologien du séparatisme ", 94-95;

"Le mysticisme racial" - À propos du groulxisme, indépendantisme, séparatisme, etc., 158-169;

"Á propos de l'Ordre de Jacques-Cartier", 179;

"À propos de la conscription ", 194;

"J.-Charles Harvey et le nationalisme de Groulx ", 189;

"Anticléricalisme de Jean-Charles Harvey ", 242, 244, 266;

"Opinion de J.-Ch. Harvey sur René Chaloult qui se réclamait de Groulx", 133;

"Groulx et la fondation du Collège Stanislas ", 133-134;

"Le mal de la désunion" - À propos de Pourquoinous sommes divisés, 139, dans Jean-Charles Harvey, précurseur de la révolution tranquille, "Collection Pensée actuelle", Beauchemin, Montréal, 1970. 
Gagnon, Serge, «Bibliographie canadienne ou les fondements de la conscience nationale ", Guide d'histoire du Canada, par André Beaulieu, Jean Hamelin, Benoît Bernier, Les Cahiers de l'Institut d'histoire, 13, Les Presses de l'Université Laval, 1969, voir 34-37, 38, 39, 40, 41, 42, 44, 50, 54, 60, 61, 334, $348,350,369,422$.

- Le Québec et ses historiens de 1840 à 1920 - La Nouvelle-France de Garneau à Groulx, "Les cahiers d'histoire de l'Université Laval ", no 23, Les Presses de l'Université Laval, Québec, 1978. VOIR "La Naissance d'une race ou l'utopie de l'unanimité ", 392-410; aussi, 11, 21, 31, 34, 186, 230, 277, 279, 288, $391,431,441$.

— «Lionel Groulx de Benoît Lacroix", Livres et auteurs québécois, 1967: 159.

Grenon, Hector, « Nos p'tites joies d'autrefois "-- Les Rapaillages. Les Éditions La Presse, Montréal, 1972, 8-9, 49.

Hamel, Réginald, John Hare, Paul Wyczynski, "Lionel Groulx", dans Dictionnaire pratique des auteurs québécois. Fides, Montréal, 1976, 321-325.

Hamel, Réginald, Cahiers bibliographiques des lettres québécoises (ler janvier au 31 mars 1967), Volume 2,1. Centre de documentation des lettres canadiennes-françaises, Université de Montréal, 1967, 318-319.

- Cahiers bibliographiques des lettres québécoises (du ler avril au 30 juin 1967), 733-743.

- Cahiers bibliographiques des lettres québécoises (1er octobre au 31 déc. 1967), Volume 2,4. p. 1641.

- Cahiers bibliographiques des lettres québécoises (janvier, février, mars 1968), p. 175.

- Cahiers bibliographiques des lettres québécoises (avril, mai, juin 1968), 145-146.

Hamelin, Pierre, "Lionel Groulx et le nationalisme canadien-français », travail présenté à la Fondation Lionel-Groulx comme participation au concours d'histoire 1975-1976. Séminaire de Québec, 1976.

Hare, John, prés., "Groulx et Tardivel", dans Jules-Paul Tardivel, Pour la Patrie - roman du 20e siècle, HMH, 1975, p. 19.

Harvey, Fernand, "V - Lionel Groulx (1878-1967)", dans Bibliographie de six historiens québécois. Institut supérieur des sciences humaines, Université Laval, octobre 1970: 27-29; 43 p. miméog.

Lachance, André, "La découverte du Canada - Jacques Cartier de Lionel Groulx ", Livres et auteurs québécois, 1966 (avril 1967): 155.

- «Roland-Michel Barrin de la Galissonière» dans Livres et auteurs québécois ", 1970, 212, 213.

Lacroix, Benoît, "Constantes de vie", dans Livres et auteurs québécois, 1967 : 181.

La Maugendre, "Notes sur Groulx ", dans La Renaissance catholique au début du 20e siècle, - Émile Baumann, Beauchesne, Paris, 1968, 98-99.

LaTerreur, Marc, Lettre de Armand Lavergne à l'abbé Groulx, le 20 novembre 1933, dans Armand Lavergne, Collection classiques canadiens, Fides, Montréal, 1968, 92-94. 
Laurendeau, André, Ces choses qui nous arrivent, Chronique des années 1961 à 1966. HMH, 1970, 53.

- "Chapter 1-1937 (Abbé Groulx)", dans Witness for Quebec, Essays selected and translated by Philipp Stratford, Macmillan of Canada, 1973, XIII, $3,57,141,166,235$.

Le Blanc, Alonzo, "L'oeuvre d'Albert Pelletier, - une satyre sociale des années 30 ", dans Voix et images du pays, VI, Presses de l'Université du Québec, 197333-49.

Lemire, Maurice, Les grands thèmes nationalistes du roman historique canadien-français, Presses de l'Université Laval, Québec, 1971, 15, 16, 17, 90, 99, 106, 172-175, 176, 233.

Mann-Robertson, Susan, "Le nationalisme de Lionel Groulx " de Jean-Pierre Gaboury, Livres et auteurs québécois, 1970, 212.

Mann-Trofimenk off, Susan, "Mes Mémoires - II", Histoire sociale, 7 (avril 1971): 110-112.

— "Mes Mémoires ", Livres et auteurs quéhécois, 1972: 258-259.

Marcel, Jean "Les forces provisoires de l'intelligence", Livres et auteurs québécois, 1965, 27-28.

Monière, Denis et André Vachet, Les idéologies au Québec, MAC, Montréal, 1976, 23, 29, 61, 62. Préface de André-J. Bélanger.

Morin, Rosaire, "Hommage à Monsieur le chanoine Lionel Groulx ", Cahiers des États généraux du Canada français, 25 novembre 1967.

Neatby, Hilda, "Lionel Groulx", dans The Quebec Act : protest and policy, Prentice Hall of Canada Limited, Scarborough, Ont., 1972, 96-98.

Nolet, Louis-Paul, "Au chanoine Lionel Groulx ", dans Biographies canadiennes-françaises, 21e édition 1968-1969, Montréal, 1968, 6-7.

«Notre choix - Histoire du Canada français " de Lionel Groulx, le livre du mois choisi par le comité de rédaction (voir no 269). Vol. 7 (sept. 1976): 4 pages.

Ouellet, Fernand, "Les insurrections de 1837-1838: un phénomène social»"L'abolition du régime seigneurial et l'idée de propriété", dans Eléments d'histoire sociale du Bas-Canada, Les Cahiers du Québec, HMH, Montréal, 1972, 297-298, 351-353.

Pallascio-Morin, Ernest, "Chemins de l'avenir", Livres et auteurs québécois, 1965: 127-128.

Renaud, Laurier, "La fondation de l'ACJC", dans Idéologies au Canada français, 1900-1929, Les Presses de l'Université Laval, Québec 1974. Coll. "Histoire et sociologie de la culture", no 5, 173-191.

Ricard, François, "Lionel Groulx, Action française, État français, dans Voix et images du pays, volume 9, (1975) : 11-33.

Robert, Jean-Claude, Du Canada français au Québec libre. Histoire d'un mouvement indépendantiste. Collection Histoire vivante, Paris, Flammarion, 1975, 167-169, 171-172, 175.

Rogers, S. John, The philosophical and literary background of FrenchCanadian nationalism; Garneau to Groulx, Western, 1958.

Rumilly, Robert, Histoire de l'École des Hautes Études commerciales 19071967, Beauchemin, 1966. - Rôle du chanoine comme professeur, 59, 68, 70, $76,77,78,84,121,142$. 
Savard, Félix-Antoine, "Citations", dans Journal et souvenirs - I - (19611962). Fides, Montréal, 1973, 161, 166, 221.

— «Lionel Groulx », Le Bouscueil, poèmes et prose. Fides, Montréal, 1972, 223-224.

Séguin, Maurice, "Lionel Groulx (1878-1967), le deuxième historien national ", dans Paul Gay, Notre littérature - Guide littéraire du Canada français à l'usage des niveaux secondaire et collégial. Éditions HMH, Montréal, 1969, 5 , $13,42,44-46,81$.

Smith, Donald, "L'Action française (1917-1921)", dans Idéologies au Canada français, 1900-1929. Les Presses de l'Université Laval, Québec, 1974. Ouvrage publié sous la direction de Fernand Dumont, Jean Hamelin, Fernand Harvey, Jean-Paul Montminy. Coll. "Histoire et sociologie de la culture ", 5, 345-346, 349-350, 355, 358, 360-361, 365, 367; voir aussi 8-11.

Sylvain, Philippe, "Mes Mémoires de Lionel Groulx", Livres et auteurs québécois, 1970: 193-198.

Sylvestre, Guy, Brandon Conron et Carl F. Klinck, "Lionel Groulx », dans Écrivains canadiens / Canadian Writers, HMH Limitée, 1964, p. 65.

Sylvestre, Guy, Gordon H. Green, "Lionel Groulx 1878-1967 - Le Canada de 1713 - aspects sociaux : les classes ", Un siècle de littérature canadienne, HMH Limitée, 1967, 100-106.

Tougas, Gérard, "Lionel Groulx (né en 1878)", Histoire de la littérature canadienne-française, Presses universitaires de France, 1964, 101-104, 137139. 141. 229, 231, 285-286.

Vachon, André, "L'affaire du Long-Sault " - valeur des sources iroquoise et française, dans Les Cahiers des Dix, vol. 40, Québec, 1975: 197-222.

Vaugeois, Denis, et al, Histoire 1534-1968 de Farley-Lamarche, Editions du Renouveau pédagogique et du Boréal Express. Montréal, 1968, voir p. 38, 74, 101, 134, 251, 376, 378, 381, 441, 456, 465, 498-499, 509, 542.

Viatte, Auguste, "L'histoire et la critique - Lionel Groulx 1878-1967", dans Anthologie littéraire de l'A mérique francophone. Université de Sherbrooke, 1971, 114-118.

Wallace, W. Stewart, ed., The Macmillan Dictionary of Canadian Biography, $4 \mathrm{e}$ ed. revised, enlarged, and updated by W.A. McKay (Toronto 1977) : 318319.

\section{ARTICLES DE REVUES}

Anonyme, "Les Chemins de l'avenir ", Idéal féminin, 14 (février 1965): 6.

"Historical Notes - The Canon and Civil War ", Time, the weekly news magazine, 86, 23 (3 décembre 1965).

"Ce mois-ci ", Aujourd'hui Québec, 2, 9 (novembre 1966): 5.

"Demain, c'est nous", lettre de L.G., Aujourd'hui Québec (mars 1967): 3.

"Liminaire en hommage au chanoine Lionel Groulx ", Recherches sociographiques, VIII, 2 (1967): 123.

"Le Québec perd un maître à penser ", Québec en bref, bull. mensuel de l'Office d'information et de publicité, Québec, 1, 4 (1967).

"La grande dame de notre histoire ", Vient de paraitre, 3, 3 (mai 1967) : 25-26. 
Éditorial - «Le jugement d'ensemble de M. le chanoine Lionel Groulx sur le rapport Parent ", L'Action nationale, 56 (mai 1967): 843-854.

"Dans la maison du Père", le Message des fondateurs de l'Église du Canada, (mai-juin 1967).

"Lionel Groulx", Relations (juillet-août 1967): 191.

"Le chanoine Groulx et le scoutisme", Le Brasier, 27, 1 (août-sept.-oct. 1967): 20-21.

"Témoignages sur le chanoine Groulx ", 17 signatures, RHAF, 21, 2 (sept. 1967) : 354-358.

"Action française", Maintenant, cahier spécial (15 septembre 1967): 289.

"Grande est la besogne, courte est la journée. Extrait d'un testament après une journée bien remplie". Le Semainier paroissial, Paroisse Saint-Maxime, Chomedey, 3 septembre 1967.

"Les lettres canadiennes françaises en deuil", Québec 67, revue du MAC, à Paris (octobre 1967): 114-118.

"L'homme", Québec 67 (octobre 1967): 118-121.

"Mes Mémoires, tomes 1-2-3, Le Canado-Américain, juillet-août-sept. 1973 : 54.

"Deux abbés, deux visions de l'histoire (Groulx, Maheux), Télé-clé 1975 : 22-24.

"Who's afraid of Lionel Groulx?", Nouvelles recherches québécoises, 1, 2 (1978) : 2-3.

"Hommage à Lionel Groulx ", Bulletin de la Bibliothèque Nationale du Québec, 12,1 (mars 1978) : 2-3.

"Groulx et 'sa' bibliothèque ", ibid., 12, 1 (mars 1978): 11.

Allaire, Georges, "Québécois que deviens-tu ? - L'éclipse d'un grand homme ", L'Action nationale, 63, 2 (octobre 1973): 134-144.

Allen, Patrick, «L'actualité sur le vif », L'Action nationale, 68, 2 (octobre 1978): 156-158.

Arès, Richard, S.J., "Mes Mémoires", Revue d'histoire de l'Amérique française, 27, 1 (juin 1973) : 105-106. - L'Action nationale (fév. 1975) : 519526.

Auger, Roland-J., "Feu le chanoine Lionel Groulx ", Mémoires de la Société généalogique canadienne-française (janvier-avril 1967): 120.

Beaudin, Dominique, "Notre abbé Groulx continue », L'Action nationale, 56, 10 (juin 1967): 10-11.

Beaulieu, Victor-Lévy, "Sur quelques livres importants publiés en 1970 », Maintenant, 103 (février 1971): 46.

Bélanger, André-J., " Mes Mémoires - III », Histoire sociale, 6, 11 (avril 1973) : 141-143.

Bélanger, Noël et Nive Voisine, "Portrait d'un homme libre: Mgr Georges Courchesne (1880-1950) », Revue du Bas Saint-Laurent, 2, 3 et 4 (décembre 1975) : 20-37.

Bilodeau, Rosario, "Les vingt ans de la RHAF", RHAF, 21, 1 (juin 1967) : 1-12.

Blain, Jean, "Économie et société en Nouvelle-France: le cheminement historiographique dans la première moitié du XXe siècle ", RHAF, 26, 1 (juin 1972) : 3-31; «Économie et société en Nouvelle-France : l'historiographie des 
années 1950-1960. Guy Frégault et l'école de Montréal", RHAF, 28, 2 (septembre 1974) : 163-186; "L'historiographie au tournant des années 1960. La réaction à Guy Frégault et à l'école de Montréal - La voie des sociologues ", RHAF, 30,3 (décembre 1976) : 323-362; voir p. 336-337.

Blain, Maurice, "Le dernier songe de Cassandre », Citélibre, 15 (mars 1965) : 3031.

Bonenfant, Jean-Charles, "Retour à Thomas Chapais", Recherches sociographiques, 15, 1 (1974) 41-55; voir surtout p. 43, 48, 51.

Boudreau, Joseph-A., "L'apolitisme des idéologies québécoises d'André-J. Bélanger", The American Historical Review, 81, 1 (février 1976): 225.

Brault, Jean-Rémi, «Hommage à Lionel Groulx », Vient de paraître, XIV, 2 mai 1978.

Brouillé, Jean-Louis, "Lionel Groulx ", L'Actualité (juillet 1967): 1.

Brunet, Michel, "Lionel Groulx, historien national ", The Canadian Historical Review, 48,3 (septembre 1967): 299-305.

- "Lionel Groulx et l'histoire de notre 'déssassimilation' ", Bulletin de la Bibliothèque Nationale du Québec, 12,1 (mars 1978) : 5-6.

Bulletin de la Bibliothèque Nationale du Québec, "Hommage à Lionel Groulx ", 12, 1 (mars 1978): 2-11; photos.

Campeau, Lucien, "Lionel Groulx, Constantes de vie", RHAF, 21, 2 (septembre 1967) : 316-317.

- «Benoît Lacroix, Lionel Groulx, textes choisis et présentés», RHAF, 21,2 (septembre 1967) : 317-318.

Caya, Marcel, "Mes Mémoires - IV", The Canadian Historical Review, 57 (mars 1976): 66-67.

Charpentier, Louise, "Histoire nationale et nationalisme", Bulletin de la Société des professeurs d'histoire du Québec, 16, 4 (octobre 1978) : 21-32.

Comeau, Robert, "Lionel Groulx, les indépendantistes de La Nation et le séparatisme (1936-1938) ", RHAF, 26, 1 (juin 1972) : 83-102; 27, 2 (septembre 1973) : 313.

Cook, Ramsay, "Le nationalisme de Groulx, de Jean-Pierre Gaboury", Histoire sociale, 6 (novembre 1970) : 135-138.

Costisella, Joseph, "Le testament du chanoine Groulx », Le Monde nouveau, 26 (février 1965) : 58-61, 75.

Crevier, Gabriel, « Nos chemins de l'avenir », Vie française, 20, 7 et 8 (mars-avril 1966) : 231-237.

Cusson, Normand, "Le chanoine Groulx, un homme finalement actuel ", TVHebdo, 21 janv. 1978.

Dagneau, G.-H., "À la mémoire de Guy Frégault ", L'Action nationale, 68, 2 (octobre 1978) : 167-171.

Daigneault, André, "L'explosion de la "bombe" de Gaulle", Aujourd'hui Québec, 3, 7 (septembre 1967): 7-11.

Denis, Raymond, "Hommage à l'abbé Groulx - une souscription", Vie française, 26, 1-2 (sept.-oct. 1971): 30-36.

Dionne, René, "L'Appel de la race" est-il un roman raciste?", Relations (novembre 1978) : 317-318. 
Duhamel, Roger, "Mes Mémoires - 1 ", Vient de paraître, 7, 1 (mars 1971).

Dumont, Fernand, "Présence de l'histoire, présence de Groulx", Bulletin de la Bibliothèque Nationale du Québe, 12, 1 (mars 1978): 6-7.

Durocher, René, "Lionel Groulx et l'histoire de l'Amérique française ", pour la revue Forces, 12 mai 1978.

Emery, Jules, S.J., "L'influence du chanoine Lionel Groulx", Bulletin de la Société des écrivains canadiens (décembre 1967): 8.

Éthier-Blais, Jean, "Mes Mémoires - I", Vient de paraître, 7 (mars 1971): 38. — "Où sont mes racines...", Études françaises, 7, 3 (août 1971) : 262-266.

Études françaises, «Marcel Dugas et son temps », 7, 3 (août 1971) : 38, 254, 263, 268 ; lettres de Lionel Groulx : 318-321.

Ferron, Jacques, "Le chanoine botté et le seigneur en chemise", Magazine Maclean, 2, 9 (septembre 1971): 46, 48.

Filion, Maurice, «Résister au temps, c'est s'inscrire dans l'histoire", Bulletin de la Bibliothèque Nationale du Québec, 12, 1 (mars 1978): 4.

Fortin, André, f.m.s., et Irénée Beaulieu, "Hommage au croûlant", Envol (1965): 17-19.

Frégault, Guy, «Lionel Groulx ", allocution au dîner annuel de l'IHAF, RHAF, 22, 1 (juin 1968): 3-16.

— «Allocution du président de l'IHAF », 17 mai 1969, RHAF, 23, 1 (juin 1969) : 3-5.

Frot, Janine, «La Femme et le nationalisme dans le roman du terroir de l'entredeux-guerres ", Voix et images, 3, 1 (sept. 1977) : 54-55.

Gagné, Jean, "Vanier et Groulx », Sept jours, 41 (24 juin 1967) : 3.

Gagnon, Serge, "Pour une conscience historique de la révolution québécoise", Cité libre, 16 (janvier 1966): 4-19.

Gay, Paul, ptre, c.s.sp., «Survol de la littérature canadienne-française - Livre deuxième: période de maturation 1900-1930 - Les Canadiens français prennent de plus en plus conscience d'eux-mêmes" - Chapitre premier: L'Histoire: Thomas Chapais - Lionel Groulx (1878-1967)", L'Enseignement secondaire, 46, 4 (sept.-oct. 1967) 22-27.

Genest, Jean, S.J., "Leurs héros et leurs idoles?", Collège et famille, 21 (avriljuin 1964): 101-110.

— "Québec ou Ottawa - III - Bourassa et Groulx ", L'Action nationale, 54 (janvier 1965): 474-482.

"À propos de Marcel Rioux ", L'Action nationale, 68, 1 (septembre 1978): 6-76.

Giguère, Georges-Émile, S.J., "Le chanoine Groulx n'est plus", Bulletin de liaison de la Société des professeurs d'histoire, 20 (avril 1967).

- «Le chanoine Lionel Groulx", Relations (novembre 1967): 292-294; reproduit, sous le titre "L'abbé Groulx et le Canada français ", dans Centre des études universitaires, Trois-Rivières (novembre 1967), 8 p.

Gingras, Marcel, "Notre maître à tous, M. le chanoine Lionel Groulx ", Vie française, 19, 11-12 (juillet et août 1965) : 330-332.

Gosselin, Paul-Émile, "Mes Mémoires ", Le Canado-Américain, 6, 5 (janvier, février, mars 1971): 23-25. 
Grégoire, Monseigneur Paul, "Lettre de Mgr Paul Grégoire à l'occasion de la campagne de souscription de la Fondation Lionel-Groulx", L'Église de Montréal (27 avril 1978): 276.

Gwyn, Julian, "Lionel Groulx », Revue de l'Université d'Ottawa, 41 (octobredécembre 1971): 567.

— «Roland-Michel Barrin de La Galissonière", de Lionel Groulx, Revue de l'Université d'Ottawa, 42,1 (janvier-mars 1972): 170.

H.R., "Lionel Groulx, l'homme de croyance", Ici Radio-Canada, 12, 5 (semaine du 28 janvier au 3 février 1978).

Jetté, Denis, "Lionel Groulx, Roland-Michel Barrin de La Galissonière", RHAF. 24,4 (mars 1971) : 602-603.

Jones, Richard, "Susan Mann-Trofimenkoff, Action française: French Canadian Nationalism in the Twenties ", RHAF, 30, 1 (juin 1976) : 121-123.

Kattam, Naïm, Les livres - «Lionel Groulx » de Benoît Lacroix, Bulletin du Cercle juif, 13, 123 (mai-juin 1967): 3.

Kempf, Yerri, "Comment peut-on être Canadien français ", Cité libre, 15 (mars 1965) : 24-26.

Lacroix, Benoît, o.p., "L'après-Groulx - à propos d'une anthologie ", RHAF : 28, 3 (déc. 1974) : 415-420.

— «Une 'première' à la Bibliothèque Nationale du Québec", Bulletin de la Bibliothèque Nationale du Québec, 12, 1 (mars 1978) : 9-10.

Lamarche, Yves, "Mes Mémoires ", Recherches sociographiques, 16 (1975): 282-288.

Lapalme, Michel, «Le nouveau chanoine Groulx s'appelle Séguin », Magazine Maclean, 6, 4 (avril 1966): 16-17.

Léger, Jean-Marc, "Sur l'ouvre", Québec 67, revue du MAC, Paris (octobre 1967) : 116-118.

Léger, Paul-Émile, cardinal, "Oraison funèbre du chanoine Lionel Groulx prononcée à l'occasion de ses funérailles en l'église Notre-Dame de Montréal, le 26 mai 1967 ", Votre Église, revue de l'Église de Montréal, 10 (9 juin 1967): 2-4.

Lesage, Germain, o.m.i., "Le nationalisme de Lionel Groulx, de J.-P. Gaboury ", RUO, 42, 3 (juillet-sept. 1972) : 482.

Lévesque, Georges-Henri, o.p., "Témoignages - La révolution tranquille Prélude à la révolution tranquille au Québec: notes nouvelles sur d'anciens instruments ", Histoire sociale, IX, 19 (mai 1977): 134-146.

Major, André, "Constantes d'une vie et d'un peuple ", Aujourd'hui Québec, 3 (juillet-août 1967): 11-12.

- "Constantes de vie du chanoine Lionel Groulx", Québec 67, 4 (octobre 1967) : 152-153.

— «Pour une pensée québécoise», Cahiers de Sainte-Marie, 4 (avril 1967): 125-131.

Malouin, Reine, "La lumière d'une âme - Hommage au chanoine Lionel Groulx ", Vie française (juillet-août 1967) : 346-350. 
Martin, Louis, "Adoncques, il se rase", Magazine Maclean (avril 1975) : 3.

Mathieu, Jacques, "Jacques Cartier - La découverte du Canada», Recherches sociographiques, 10 (janvier-avril 1969) : 132-133.

May, C.R.P., "French Canada through history and poetry", Alta, The University of Birmingham Review, 5 (Spring 1968) : 282-285.

Migner, Robert, "D’abord une affaire de gros sous ", Zone libre - album de famille (juin-juillet 1978).

Morin, Rosaire, "Hommage posthume à Lionel Groulx - Les États généraux du Canada français - assises nationales 1967 ", L'Action nationale, 57, 6 (février 1968): 10-11.

Mudrock, V. "The abbé Groulx - History as a Weapon ", Queen's Quarterly, 63 (été 1956) : 179-187.

M.P., "L'œuvre de M. le chanoine Lionel Groulx », Défense la langue française, no 23 (juillet 1964): 28. Reproduit dans Vie française (sept.-oct. 1964) : 29. 1964) : 29.

Ouellet, Fernand, "Le nationalisme canadien-français; de ses origines à l'insurrection de 1837 », CHR, 65, 4 (décembre 1964) : 277-278.

— «Historiographie canadienne et nationalisme», MSRC, 4, 13 (1975) : 2538.

Parizeau, Gérard, «Le chanoine Lionel Groulx », Assurance (juillet 1967) : 159160.

Pelletier, Albert, «À propos de L'avenir de notre bourgeoisie - Les idées 19351939 ", Écrits du Canada franşais, 34 (Montréal, 1972) : 89-95.

Poulat, Émile, "Le nationalisme de Lionel Groulx", Archives des sciences sociales des religions, 33 (janvier-juin 1972) : 299. — «Roland-Michel Barrin de La Galissonnière", ibid. : 285.

Pritchard, James, "Mes mémoires - I", Histoire sociale, 7 (avril 1971) : 104109.

Richard, J., "Orientations - mises en garde", Annales de Bourgogne, 37 (1965).

Richer, Julia, «(Juliette Lalonde-Rémillard) - L'homme que j’ai connu », L'Actualité (juillet 1967): 7-9.

- «Hommage à Lionel Groulx", Vient de paraitre, 3, 4 (sept. 1967) : 21.

_ «Un beau texte de Lionel Groulx », L'Action nationale, 9 (mars 1971) : 594595.

- «Un demi-siècle d'histoire et de combat ", Lectures 66 (5 janvier 1966) : 133.

Rioux, Albert, "Groulx et notre avenir national ", L'Action nationale, 68, 1 (sept. 1978) : 23-26.

- "De Lionel Groulx à Marcel Rioux", L'Action nationale, 68, 3 (nov. 1978) : 252-254. Lettres d'Albert Rioux.

Rivet, Jean-Paul, «Prêtre et historien », L'Église de Montréal, 96e année, 20 (18 mai 1978) : 323 .

Robitaille, Georges, "Être maître chez soi", Relations (juillet 1964): 213.

Roy, Clément, "Hommage à Guy Frégault ", Monongahela, 1, 1 (septembre 1978): $4-5$. 
Sabella, Lily, «Monsieur le chanoine Lionel Groulx ", Trait d'union, revue de la paroisse St-Sauveur de Montréal, 4, 3 (juillet-août 1967): 3.

Saint-Onge, Paule, "Châtelaine a lu pour vous", Châtelaine (nov. 1966): 17.

Saint-Yves, Jacques, "Les impropères de M. Claude Ryan", L'Action nationale, 54 (février 1965): 628-631.

Savard, Pierre, "Un quart de siècle d'historiographie québécoise, 1947-1972 ", Recherches sociographiques, 15, 1 (1974): 77-96.

- "Lionel Groulx actuel et inactuel ", Bulletin de la Bibliothèque Nationale du Québec, 12, 1 (mars 1978): 7-8.

Stratford, Philip, "Quebec Books ", The Globe Magazine (2 juillet 1966) : 15.

Sutherland, Ronald, "Twin Solitudes", Canadian Literature, 31 (hiver 1967): 5-24.

— "The Body-odour of race", Canadian Literature, 37 (été 1968) : 46-47.

Taschereau, Yves, "Des mémoires de Lionel Groulx », S.P.L., Montréal, 3, 37 (21 juin 1978).

Thériault, Yves, "Un grand Canadien", Sept Jours, 38, 3 (juin 1967): 10-12.

Torrelli, Maurice, "Charles Maurras et le nationalisme canadien-français", L'Action nationale (octobre 1977): 103-113.

Tremblay, Jean-Noël, «Allocution au banquet du 20e anniversaire de la RHAF, $R H A F, 21,1$ (juin 1967): 13-15.

Trépanier, Pierre, "Ex-libris, le Canada anglais et ses historiens", L'Action nationale (sept. 1977) : 75-78.

— «À quoi servent les historiens », L'Action nationale, 67, 6 (fév. 1978) : 447451.

— «Pour mieux connaître Groulx », L'Action nationale, 68, 3 (nov. 1978): 209-218.

Trudel, Jean-Paul, "Propos aigres doux d'un fossile de cinquante ans", Le Ralliement (Trois-Rivières), 7,5 (7 février 1967): 10-11.

Trudel, Marcel, "Les débuts de l'Institut d'histoire à l'Université Laval", RHAF, 27, 3 (déc. 1973) : 397-402.

Upton, L.F.S., "In search of Canadian History ", Queen's Quarterly, 74, 4 (hiver 1967) : 680-681.

Vadeboncour, Pierre, "A break with Tradition? Political and Cultural Evolution in Quebec", Queen's Quarterly, 65 (printemps 1958) : 92-103.

Verrette, Adrien, p.d., "Témoignage : Lionel Groulx, 1878-1967", Le CanadoAméricain, 5, 2 (avril-mai-juin 1967): 18-23.

Viatte, Auguste, "Chronique des lettres françaises hors de France : le Canada", Conjonction - revue franco-haïtienne - (octobre 1967): 5-11.

Voisine, Nive, "La production des vingt dernières années en histoire de l'Église du Québec ", Recherches sociographiques, 15, 1 (1974): 97-112. - «Main basse sur le passé ", Hommage à Lionel Groulx sous la direction de Maurice Filion, Lettres québécoises, 10 (avril 1978): 48, 50.

Wade, Mason, "Mes mémoires", The Canadian Historical Review, 53 (déc. 1972) : 458-469.

Wallot, Jean-Pierre, "D'une conquête aux bombes... l'histoire", Lettres et écritures, 1 (avril 1964): 18-24. 
Zoltvany, Yves F., "Rolland-Michel Barrin de La Galissonière », The Canadian Historical Review (déc. 1971): 429-430.

\section{ARTICLES DE JOURNAUX SIGNÉS}

Allard, Maurice, "Le chanoine Groulx", JOURNAL DE SHERBROOKE, 2 juillet 1967 , p. 3 .

A., M., "Le testament du chanoine Groulx", LE DEVOIR, 27 mai 1967.

Angers, François-Albert, "Offensive la plus astucieuse jamais conçue pour dénationaliser les Canadiens français ", L'INFORMATION NATIONALE, février 1965.

- «Une province comme les autres", MONTRÉAL-MATIN, ler février 1965.

A.P., "Chez Fides, lancement de son dernier ouvrage ", LA PRESSE, 24 mai 1967.

Arès, Richard, "Quelques témoignages", LE DEVOIR, 24 mai 1967.

Arteau, Odilon, "M. le chanoine Lionel Groulx et le Comité des Fondateurs", L'ACTION, 13 juin 1966, p. 4.

- «Il y a vingt ans naissait la Revue d'histoire de l'Amérique française», L'ACTION, 15 avril 1967.

— «Un projet qui mérite l'appui de la population», L'ACTION, 16 janvier 1970.

- «À propos du fameux manuel unique", L'ACTION, Québec, 9 février 1970.

Barbeau, Victor, "Des témoignages de tous les coins du Québec ", LA PRESSE, 24 mai 1967.

Barrette, Roland, "Dans ses Mémoires, le chanoine Groulx a tenu à dire toute la vérité ", DIMANCHE-MATIN, 25 octobre 1970, p. 169.

Basile, Jean, "Réflexions sur le Salon du Livre", participation des poètes et écrivains, comme le chanoine Lionel Groulx, LE DEVOIR, 17 avril 1965.

Bastien, Hermas, "Mémoires d'une vie», L'INFOR MATION MÉDICALE ET PARAMÉDICALE, 16 février 1971, p. 28.

Beaudin, Dominique, "Le chanoine Lionel Groulx et la Ligue d'Action nationale", LE DEVOIR, 25 mai 1967, p. 5 ; LE DROIT, 31 mai 1967, p. 6.

Beaudoin, Benoît, "Ainsi parle un homme libre!»: Chemins de l'avenir, du chanoine Lionel Groulx ", CARREFOUR CHRÉTIEN, 11 février 1965.

Beaudoin, Jean-Marc, "Hommage à l'abbé Lionel Groulx », LE NOUVELLISTE, 12 juin 1968 , p. 16, col. 4-5.

Beaulieu, Ivanhoë, «Un cheminement vers la conscience », LE SOLEIL, 24 octobre 1970.

— «Une certaine géographie intérieure - Jean Éthier-Blais publie la condition québécoise (Signets III)", (influence de Groulx), LE DEVOIR, 16 juin 1973.

Beauregard, Luc, "Le chanoine Groulx accuse le Canada anglais d'être raciste", LA PRESSE, 13 avril 1964.

Bégin, Cécile, «Réflexions autour d'un témoignage", L'ACTION, 16 juin 1967.

Bégin, Émile, "Hommage à feu le chanoine Groulx », L'ACTION, 23 juin 1967, p. 23.

Bélanger, André-J., "Lionel Groulx et le culte du chef", - Éviter de donner l'acception péjorative d'après-guerre aux mots du chanoine ", LE JOUR, 30 janvier 1975, p. 9. 
Bélanger, Yvan, "Le parc situé à l'arrière de l'église St-Augustin est baptisé parc Lionel-Groulx ", LE PROGRĖS DE VALLEYFIELD, 26 avril 1978.

Bellemare, André, "L'ombre du chanoine Groulx plane sur notre fête nationale", LE NOUVELLISTE, 23 juin 1967.

Benoît, Michel, "Sa voix a frappé de plein fouet les indécis, les hésitants et les incrédules", MONTRÉAL-MATIN, 27 mai 1967.

- "Mille convives rendent un vibrant hommage au chanoine Lionel Groulx", MONTRÉAL-MATIN, 23 juin 1967.

Bernard, Antoine, "Un grand disparu, Lionel Groulx", LE TRAVAILLEUR, 8 juin 1967. p. 1, 2.

Bernier, Conrad, "Reponse à un lecteur courroucé (à propos de Charles de Gaulle)", LE PETIT JOURNAL, le 6 août 1967.

- "Apartés", LE PETIT JOURNAL, vol. 41, no 50, 5 octobre 1967.

- «Avec Chemins de l'avenir, Lionel Groulx s'est interrogé sur la valeur de la jeunesse québécoise ", LE PETIT JOURNAL, semaine du 8 octobre 1967, p. 66.

Bernier, Gérald, "Le chanoine Groulx dans le vent et dans les patates ", LE QUARTIER LATIN, 47, 11 février 1965, p. 8.

Bernier, Germaine, "Si le chemin se parcourt avec les pieds, la direction du voyage doit être confiée à la tête ", LE DEVOIR, 29 juin 1964, p. 8.

Bertrand, André, "Lionel Groulx, par l'image ", LA PATRIE, 22 décembre 1968, p. 61 .

Blouin, Jean, "Un homme seul contre l'Establishment de son temps: Lionel Groulx ", PERSPECTIVES, LA PRESSE, 10 juin 1978, p. 16, 17, 18, 20 et 21.

B., L., «Décès du chanoine Lionel Groulx », LA VOIX DES MILLE-ILES, 25 mai 1967, p 3.

Boisclair, Paul-André, "Le Dr Jacques Ferron et l'histoire », LA PRESSE, 28 juin 1971.

Bolduc, Roger, "Ce que nous devons au chanoine Groulx", L'ÉCLAIREURPROGRĖS, 31 mai 1967, p. 4.

Bonenfant, Jean-Charles, "Un homme d'une vigueur extraordinaire", LE SOLEIL, 24 mai 1967, p. 23.

— «'abbé Lionel Groulx", L'ACTION, ler juin 1967, p. 4.

Bonin, René, "Le chanoine Groulx", LA PATRIE, 28 mai 1967.

Boulanger, Georges, "Graves erreurs d'un éminent historien", L'OPINION, 11 avril 1965 , p. 2.

— «Un grand héros national ", LE DEVOIR, 31 août 1972.

Bourbonnais, Denis, "Colloque pour le centenaire Lionel Groulx", LE STFRANÇOIS, Valleyfield, 26 avril 1978.

Bourgault, Pierre, "Le chanoine Groulx" (éditorial), L'INDÉPENDANCE, ler au 15 juillet 1967 .

Bousquet, Denis, "Témoignages ", MONTRÉAL-MATIN, 24 mai 1967.

- "C'est la voix de Groulx ", LA PRESSE, 27 juillet 1967.

Brault, François, "Au sujet d'un document sur Lionel Groulx ", LE DEVOIR (lettre), 13 mai 1978. 
Brochu, Michel, «Une suggestion: perpétuer dans la géographie le nom du chanoine Lionel Groulx ", LE DEVOIR, 26 mai 1967, p. 6.

- «Pour une grande rue de Montréal en l'honneur du chanoine Groulx", LE DEVOIR, 18 mai 1968, p. 4.

Brodeur, Jean-Paul, «La philosophie du passé méconnu de la pensée québécoise ", LE DEVOIR, 3 mai 1975.

Brousseau, Gérard, "L'unilinguisme, et rien de moins", LE DEVOIR, 24 novembre 1965.

Brousseau, Jacques, "L'abbé Groulx n'est plus », MONTRÉAL-MATIN, 25 mai 1967; LA PROSPÉRITÉ, mai 1967.

Brunel, Marie-Lise, "Ses propos d'actualité », entrevue accordée le 25 mars 1967 et enregistrée sur bande magnétique, LA PRESSE, 27 mai 1967.

Brunet, Godias, "M. le chanoine Lionel Groulx », LE DEVOIR, 3 juin 1967, p. 5; LE DROIT, Ottawa, 3 juin 1967.

Brunet, Michel, "Le mouvement séparatiste tire son inspiration de Groulx ", LA PRESSE, 6 avril 1964.

— «Quelques témoignages", LE DEVOIR, 24 mai 1967.

- «Texte de l'éloge du chanoine Lionel Groulx prononcé au Hall d'honneur de l'Université de Montréal, le 25 mai 1967 ", LA PRESSE, 5 juin 1967, p. 4 ; LE DEVOIR, 29 mai 1967, p. 5.

B., R., "Le chanoine Groulx", LA PATRIE, 28 mai 1967, p. 19.

Castonguay, Yvon, "Un an après sa mort, ce grand disparu est toujours vivant", L'ÉCHO DE VAUDREUIL-SOULANGES, 22 mai 1968.

Chaloult, Pierre, "Honni soit qui mal y pense", LE JOUR, 10 juin 1977, 15-16.

— « À $\$ 5.00$ par cours, le chanoine Groulx a tracé la vraie voie aux Canadiens français ", LA PATRIE, semaine du 28 novembre 1965, p. 9.

- «Moins ça change, plus c'est pareil », - P.C. compare le nationalisme de sa jeunesse à celui d'aujourd'hui, LA PATRIE, 19 décembre 1965.

- «Lionel Groulx était le principal orateur d'une fête du souvenir, en son honneur ", LE SOLEIL, Québec, 29 juin 1978.

Champoux, Roger, "Maître en leçons d'énergie", LA PRESSE, 26 novembre 1965 , p. 4.

- «Le phare brillera toujours", LA PRESSE, 25 mai 1967, p. 4.

Chaput-Rolland, Solange, "Unravelling soul of Quebec - To read two vies is to know Canada ", THE GAZETTE, mars 1971.

Charette, Soeur Simone, "Un grand ami du collège Basile-Moreau, disparaît ", L'ÉCHO DE SAINTE-CROIX, juillet 1967, numéro 3.

Chevalier, Willie, "Chemins de l'Avenir du chanoine Lionel Groulx ", LE DROIT, 5 janvier 1965 , p. 6.

- "Contre des calomnies", LE DROIT, 18 octobre 1965, p. 6.

— "Lionel Groulx, ptre", LE DROIT, 24 mai 1967, p. 6.

- «Trop d'anesthésistes", LE DROIT, ler juin 1967, p. 6.

- "Cent ans d'histoire 1867-1967. La Revue d'histoire de l'Amérique française", LE DROIT, 9 février 1968.

Chicoine, René, «Charles Maurras et le chanoine Lionel Groulx », LE DEVOIR, 4 octobre 1977. 
Cliche, Robert, "Quelques témoignages", LE DEVOIR, 24 mai 1967.

Cliff, Dominique, "Continuity of Nationalism", THE MONTREAL STAR, 7 octobre 1975.

Cloutier, Gilles, "Trois abbés...", ALLO-POLICE, 4 juin 1967, p. 26.

Colpron, Bruno, "Le chanoine Groulx", LE DEVOIR, 3 juin 1967, p. 5.

Cook, Ramsay, "De l'usage et de l'utilisation de l'histoire "(Rapport Parent), LE DEVOIR, 6 février 1965, p. 4.

- "Quelques témoignages", LE DEVOIR, 24 mai 1967.

Cormier, Guy, "Un hôte peu accueillant ", LA PRESSE, 10 février 1964.

- «Le langage inflationnaire", LA PRESSE, 20 avril 1964.

- «Feu le chanoine Groulx", LA PRESSE, 24 mai 1967.

- «La trahison des clercs», LE DEVOIR, 11 février 1978.

Costisella, Joseph, "Le testament du chanoine Groulx », LE TRAVAILLEUR, 18 février 1965, p. 1, 3.

- «Du temps vers l'Éternité - Lionel Groulx 1878-1967», LE TRAVAILLEUR, Worcester, Mass., 22 juin 1967, p. 1 et 6.

Côté, Maurice, "On doit tout au chanoine Lionel Groulx", LE JOURNAL DE MONTRÉAL, 26 novembre 1965.

Coucke, Paul, "Quelques étudiants montréalais sortent de leur tour d'ivoire", LE JOURNAL DE MONTRÉAL, 12 février 1965, p. 6.

C., P., "Le chanoine Groulx continue sa lutte ", LA TRIBUNE, 11 mars 1965, p. 8.

- "Aux yeux du chanoine Groulx", LE NOUVELLISTE, 11 mars 1965, p. 4.;

- "Le chanoine Groulx ne dételle pas », LA VOIX DE L'EST, 13 mars 1965, p. 2.

C., R., "Le chanoine Groulx a 88 ans ", LE DEVOIR, p. 4.

Cromp, Joseph. A., "En potinant», LE BIEN PUBLIC, 2 juin 1967.

- "L'opinion de Jos. A. Cromp ", LE JOUR NAL DE MONTRÉAL, 2 juin 1967.

Cusson, Normand, "Le chanoine Groulx, un homme finalement actuel", TV HEBDO, semaine du 21 janvier 1978, p. 141A.

Dagenais, André, «Hommage à Lionel Groulx ", PLEINS POUVOIRS nos 7 et 8 , du ler au 31 mai 1968.

Dagenais, Angèle, "Vient de paraître: Notre grande aventure ", LE DEVOIR, 17 janvier 1977, p. 11.

- «Lionel Groulx, cet éveilleur national », LE DEVOIR, 25 juin 1977.

Daigneault, Richard, "Abbé Groulx' books provide insight into current events ", THE MONTREAL STAR, 11 octobre 1977.

Dallaire, Thérèse, "Le concours Lionel-Groulx un événement qui se reproduira...", INFOR MEQ, déc. 1978, p. 17.

Da Silva, Maurice, "Société Historique de Montréal», LE TRAVAILlEUR, mars 1978.

Denis, Fernand, «Souvenirs personnels de Fernand Denis sur le chanoine Lionel Groulx" - "L'autre chanoine Lionel Groulx que j'ai connu ", LE PETIT JOURNAL, semaine du 28 mai 1967, p. 4-5.

Deschênes, Gaston, "Henri Bourassa séparatiste?", LE DEVOIR (lettre), 23 octobre 1974.

Deslauriers, Jacques, "90 années consacrées au service de la nation canadiennefrançaise ", L'ÉCHO DE VAUDREUIL-SOULANGES, 31 mai 1967, p. 2425. 
— «Le jour de sa mort le chanoine Groulx devait assister au lancement de son dernier volume ", L'ÉCHO DE VAUDREUIL-SOULANGES, 31 mai 1967.

Desmarteau, Charles, "En la personne du chanoine Lionel Groulx, la voix du Québec s'éteint paisiblement...", LA SEIGNEURIE, Boucherville, semaine du 22 au 26 mai 1967.

Desprez, Jean, "Lettre ouverte au vénérable chanoine Groulx", MÉTROEXPRESS, 28 janvier 1965; voir aussi de Jean-Charles Harvey, une femme forte ", LE PETIT JOURNAL, 7 février 1965.

Deyglun, Henri, «Pèlerinage de La Semaine à la maison du chanoine Groulx. Sa nièce veille sur son héritage ", LA SEMAINE, semaine du 23 au 29 septembre 1968.

Dion, Denis, “Un homme simple passionné d'histoire», LE JOUR, 13 janvier 1978.

- «Lionel Groulx et le nationalisme », LA PRESSE, 23 septembre 1978, p. D 3.

Dion, Jean-Luc, "Père spirituel de la nouvelle nation québécoise", LE NOUVELLISTE, 26 mai 1967, p. 4.

Dionne, Louis-René, "L'abbé Groulx nous a laissé un testament », LE JOUR, 17 juin 1974 (lettre au Jour).

Dionne, Raymond, "Historian Groulx Spurns Neutrality», THE MONTREAL STAR, 25 novembre 1965.

Dostie, Gaétan, "Les 15 ans de Boréal Express », LE JOUR, 25 février 1977.

Drapeau, Jean, «Le chanoine Groulx ne nous a pas quittés; sa pensée nous reste ", MONTRÉAL-MATIN, 24 mai 1967.

- «Des témoignages de tous les coins du Québec », LA PRESSE, Montréal, 24 mai 1967.

— «L'hommage de Jean Drapeau», LE DEVOIR, 24 mai 1967.

- "Il tirait du destin tragique de notre peuple une leçon d'énergie et de confiance", LE JOURNAL DE MONTRÉAL, 24 mai 1967.

Drolet, Jean, "Le Québec a rendu hier un ultime hommage au chanoine Lionel Groulx ", LE DEVOIR, 27 mai 1967, p. 1.

Dufresne, Yves, "Lettre au Devoir", LE DEVOIR, ler mars 1978.

Dugas, Jacqueline, "Lettre au Devoir", LE DEVOIR, 3 mars 1978.

Duhamel, Roger, "Un Napoléonide en visite au Canada", LE DROIT, 4 septembre 1965 , p. 7.

— «Fin de partie ou les repentirs retardés», LE DROIT, 17 juin 1967, p. 12.

- "La haute exigence du chanoine Groulx", PHOTO-JOUR NAL, 20-27 juillet 1966, p. 52.

— "La revue des trompés", par le sergent Victor Barbeau", LE DROIT, 24 septembre 1966, p. 25.

- "La grande dame de notre histoire", PHOTO-JOUR NAL, 19 octobre 1966, p. 63.

-_ «Quelques témoignages", LA PRESSE, 24 mai 1967.

- «Sur la pensée du chanoine Lionel Groulx », LE DROIT, 3 juin 1967, p. 16.

- "Un grand serviteur de la cause canadienne-française", LE DROIT, 14 novembre 1970 , p. 7. 
Dumont, Fernand, “Mémoire de André Laurendeau », LE DEVOIR, 6 mai 1968. - «Souvenir et présence de Lionel Groulx», LE DEVOIR, 25 mai 1972, p. 5, (allocution).

Dupire, Jacques, "La grande dame de notre histoire », ÉCHOS-VEDETTES, 3 septembre 1966, p. 23.

Dupuis \& Frères, "Hommage au très regretté chanoine Lionel Groulx ", LA PRESSE, 24 mai 1967.

Duval, Monique, "Le chanoine Lionel Groulx nous a légué le goût de l'histoire ", LE SOLEIL, ler juin 1977.

— «Cérémonie, à l'occasion du 10e anniversaire du décès de Lionel Groulx ", LE SOLEIL, ler juin 1977.

- «Notre État français nous l'aurons! (Groulx, 30 juin 1937)", LE SOLEIL, 29 juin 1977.

Éthier-Blais, Jean, "Une historique continuité », LE DEVOIR, 8 février 1964, p. 14.

- «L'enseignement de l'histoire", L'INFORMATION NATIONALE (SSJB de Montréal), mars 1964.

— «Le chanoine Lionel Groulx", LE DEVOIR, 30 mai 1964, p. 11.

- «Lettres et sciences», LE DEVOIR, 18 juillet 1964, p. 12.

- "Chemins de l'avenir du chanoine Lionel Groulx", LE DEVOIR, 9 janvier 1965 , p. 12.

— «On a entièrement déformé mes propos de Toronto sur le clergé et la langue ", LE DEVOIR, 25 février 1965, p. 4.

- "La grande dame de notre histoire par le Chanoine Lionel Groulx", LE DEVOIR, 30 juillet 1966, p. 8.

- «La tâche du critique et la réaction de la piété filiale ", LE DEVOIR, 20 janvier 1967.

— «Des témoignages de tous les coins du Québec», LA PRESSE, 24 mai 1967.

- «Aspects de Groulx ", LE DEVOIR, 26 mai 1967, p. 6.

— «Souvenirs de Lionel Groulx », LE DEVOIR, 28 décembre 1968, p. 10.

— «Vision du nationalisme de Lionel Groulx », LE DEVOIR, 25 juillet 1970, p. 9.

- "Le nationalisme dans les romans historiques canadiens-français", LE DEVOIR, 31 octobre 1970, p. 12.

— «Un Noël de lecture", LE DEVOIR, 12 décembre 1970.

— «Lionel Groulx » - discours de réception à l'Académie canadienne-française : "Ce coeur puissant a assumé l'amour d'un peuple vaincu ", LE DEVOIR, 11 décembre 1971, p. 18.

Faribault, Marcel, "Quelques témoignages", LE DEVOIR, Montréal, 24 mai 1967.

Favreau, Marianne, "On a oublié de définir quelle sorte d'hommes ou de société on veut former ", LA PRESSE, 25 novembre 1974.

Felteau, Cyrille, "Retour à Québec", L'ACTION, mars 1971.

— «Qui est le vrai père du fleurdelisé ?", LA PRESSE, 20 janvier 1973, p. B7.

— «L'indépendance viendra de nos dirigeants politiques acculés à de fatales impasses " (le chanoine Groulx), LA PRESSE, 9 décembre 1974, p. A6.

- "Les Mémoires du chanoine Lionel Groulx jettent une lumière nouvelle sur 'L'affaire Charbonneau' ", LA PRESSE, 12 et 13 décembre 1974, p. A5. 
- «Papineau a bel et bien été inhumé dans sa chapelle» - extraits de Notre maître, le passé, LA PRESSE, 12 février 1975.

— «étrospectives de nos grandes batailles linguistiques", LA PRESSE, 4 avril 1977.

Ferland, Guy, "Le chanoine Groulx expose sa conception de l'histoire " - pour marquer le 50e anniversaire de son premier cours, LE DEVOIR, 25 novembre 1965.

Ferland, Joseph, "Lettre au Devoir, Chemins de l'avenir, " LE DEVOIR, 21 janvier 1965.

Ferron, Jacques, «Le cabinet des antiques », L'INFOR MATION MÉDICALE ET PARAMÉDICALE, 5 juin 1973.

- Lettre de Paul-André Boisclair, professeur d'histoire, au Dr Jacques Ferron, intitulée: "Le Dr Ferron et l'histoire», LA PRESSE, 28 juin 1971.

- «Lionel Groulx et le nationalisme noir », LE JOUR, 13 janvier 1978.

Ferron, René, «Mes Mémoires », LE PETIT JOURNAL, 20 décembre 1970, p. 82.

- «L'histoire doit vivre comme un roman », PERSPECTIVES, LA PRESSE, 12 juin 1971.

Filion, Gérard, "Quelques témoignages ", LE DEVOIR, Montréal, 24 mai 1967.

Fortin, Georges-Henri, "Allocution, 26 mai 1968, ler anniversaire de la mort du chanoine Groulx ", LE DROIT, 30 mai 1968; L'INFORMATION NATIONALE, juillet août 1968 .

Fox, Cy, «Le chanoine Groulx à 87 ans demeure le champion de la cause du Canada français", LE DROIT, 11 mars 1965, p. 17.

- «À 87 ans, le chanoine Groulx reste résolument tourné vers Notre maître le passé", LA PRESSE, 12 mars 1965, p. 5.

- «At 87, Canon Groulx is still crusading", THE WINNIPEG TRIBUNE, 13 mars 1965 .

- «À 87 ans, le chanoine Lionel Groulx poursuit son rôle de champion de la cause du Canada français ", L'ACTION, 15 mars 1965, p. 7.

Fradet, Léandre, "Une invitation des Amis de Lionel Groulx", LE DEVOIR, 17 juin 1978, p. 4.

- «Le centenaire de Lionel Groulx», LE DEVOIR, 18 novembre 1978.

- "Les amis de Lionel Groulx n'oublient pas ", LE SOLEIL (lettre), 22 novembre 1978.

Francour, Jacques, "Le chanoine Groulx : des gestes positifs feront plus qu'une loi pour établir l'unilinguisme ici", DIMANCHE-MATIN, 21 novembre 1965.

- «Monument au chanoine Lionel Groulx, à Vaudreuil?", DIMANCHEMATIN, 2 juillet 1967.

- "Tous les aspects de l'oeuvre de Groulx scrutés à la loupe", DIMANCHEMATIN, 8 octobre 1978, p. 38.

Frégault, Guy, "Chez Fides, hier soir, hommages de... Guy Frégault ", LE DEVOIR, 24 mai 1967.

- «Des témoignages de tous les coins du Québec", LA PRESSE, Montréal, 24 mai 1967, p. 21. 
- «Hommage au chanoine Groulx - l'historien fut marqué par son époque ", LE DEVOIR, 13 et 14 mai 1968. Reproduit dans PLEINS POUVOIRS, vol. 1, nos 7 et 8, du ler au 31 mai 1968.

— «L'historien a dominé son temps", LE DEVOIR, 14 mai 1968, p. 5.

— «Guy Frégault évoque une sombre prédiction de Lionel Groulx », LA PRESSE, 15 mai 1968.

- «Lionel Groulx, témoin de la fidélité et de l'objectivité vivante en histoire ", LE DEVOIR, 20 mai 1969, p. 4.

Gagné, Jean, "Les anciens Canadiens: Vanier et Groulx », LE DEVOIR, 28 juin 1967, p. 4.

Gagné, Roland, “Le chanoine Groulx ", LA VOIX DE L'EST, 26 mai 1967, p. 4. Gagnon, Fernand, "On croit entendre la voix du chanoine Lionel Groulx", LE NOUVELLISTE, 22 juin 1968, p. 20.

Gagnon, Jean-Louis, "Les hommes seront toujours plus importants que les structures ", LE JOURNAL DE MONTRÉAL, 6 avril 1965.

- "Le Rapport Parent et le nationalisme québécois", JOURNAL DE MONTRÉAL, 26 avril 1965, p. 17.

- «Hommage à Lionel Groulx», LE DEVOIR, 24 mai 1967.

— «Lionel Groulx et le nationalisme», LE DEVOIR, 29 mai 1967, p. 5.

Gagnon, Marcel-A., "L'ami des auteurs débutants ", LE DEVOIR, 29 mai 1967.

Gagnon, Serge, «Jamais le Canada français n'a voulu d'un État central fort - Pas de carcan (chanoine Lionel Groulx)", L'ACTION, Québec, 8 juin 1964.

Gariépy, Gilles, "La 'Revue d'histoire' témoigne depuis 20 ans ", LE DEVOIR, 15 avril 1967, p. 11.

Gariépy, Renault, «Le chanoine Groulx à Canadiana », LA PRESSE, 24 mai 1967.

Gascon, Denis, "En marge de Groulx: Analyses du Québec", McGILL DAILY, 17 octobre 1978, p. 5.

Gaudet-Smet, Françoise, "Courtepointes: Ce n'est pas prendre la place des autres que de prendre la nôtre ", LA TRIBUNE, Sherbrooke, 23 janvier 1965.

— «Un signe", LA PRESSE, 30 mai 1967.

- [ Hommage ], LA TRIBUNE, Sherbrooke, 3 juin 1967.

Gauvin, Charles-Julien, "Le chanoine Groulx, source d'inspiration », PROGRÈSDIMANCHE, 28 mai 1967, p. 4.

Gay, Paul, "La découverte du Canada», LE DROIT, 28 mai 1966, p. 12.

- «Un père de la patrie : le chanoine Lionel Groulx ", LE DROIT, 26 mai 1967.

- «Constantes de vie", LE DROIT, 24 juin 1967, p. 16.

— «Le relèvement de la conscience nationale ", 1-LE DROIT, 12 juin 1971, p. 7 ; 219 juin 1971 , p. $7 ; 3-26$ juin 1971, p. 7.

G., C., "Humble hommage au chanoine Lionel Groulx", LE PROGRÈS DE VILLERAY, 31 mai 1967.

Gendron, Claude, "Le chanoine Groulx a réveillé toute une génération endormie " - (le cardinal Léger), LA PRESSE, 26 mai 1967.

Gérin-Lajoie, Paul, "Vaudreuil a perdu son fils le plus illustre », L'ÉCHO DE VAUDREUIL-SOULANGES, 7 juin 1967, p. 6.

Gervais, Émile, S.J., "Le chanoine Groulx et les fondateurs de l'Église du Canada ", LE DEVOIR (lettre), avril 1978. 
Giguère, Georges-Émile, «Au rang des Chenaux », - Centenaire de la naissance de Lionel Groulx, LE JOUR, 13 janvier 1978.

Gingras, Marcel, "Notre maître à tous, M. le chanoine Lionel Groulx", LE DROIT, 10 mai 1965, p. 6.

— «Le goût de grands et beaux risques ", LE DROIT, Ottawa, 27 mai 1967, p. 6.

— «Un timbre s'impose», LE DROIT, Ottawa, 7 juin 1967.

- « 24 juin - la fête du Canada français », LE DROIT, Ottawa, 21 juin 1968.

- «Les vingt-cinq ans d'une Revue», LE DROIT, Ottawa, 10 mai 1972, p. 6.

Girard, Jogues, «Les professeurs d'histoire se penchent sur le chapitre du Rapport Parent qui les concerne", LA PRESSE, 20 décembre 1965.

Girard, Monique, "Deux concours ouverts aux étudiants dans le but de faire connaître le chanoine Lionel Groulx ", LE JOURNAL DE MONTRÉAL, 12 février 1976.

Giraud, Marguerite, «Du Séminaire de Sainte-Thérèse au Cégep Lionel-Groulx Des débuts très modestes, 150 ans d'enseignement, 10,000 anciens élèves ", PERSPECTIVES, 26 juillet 1975 , no 30.

Giroux, Maurice, "La disparition du chanoine Lionel Groulx - vaste remise en question de son ouvre historique ", LA PRESSE, 27 mai 1967, p. 5.

Gobeil, J.-G., "Hommage au chanoine Groulx", L'ACTION, 14 juin 1967, p. 5.

— «En souvenir du chanoine Groulx», LE DEVOIR, 16 juin 1967, p. 4.

— "Hommage posthume à l'abbé Groulx", LE DROIT, 24 juin 1967, p. 7.

Godbout, V., «Enseignement de l'histoire", lettre ouverte, L'ACTION, 8 février 1965 , p. 4.

Gosselin, Paul-Émile, Mgr., "On s'apprête à nous enseigner notre histoire comme celle d'un autre pays ", LE DEVOIR, 22 janvier 1965.

Gouin, Jacques, "Sur les Chemins de l'avenir", LE DROIT, 9 juin 1965, p. 6.

- «Les Mémoires de Lionel Groulx », LE DROIT, ler février 1975.

- "Hommage à un grand historien, un grand patriote", JOUR NAL DES PAYS D’EN HAUT, 9 février 1978, p. 4.

Goulet, Antoine, "De l'Histoire, Lumière des Nations ", LE TRAVAILLEUR, 6 avril 1967.

— «Histoire, Biographie, Folklore", LE TRAVAILLEUR, 11 janvier 1968, p. 1.

- "Mes Mémoires", tome II, LE TRAVAILLEUR, 14 octobre 1972.

- «Mes Mémoires", tome 3 et 4, LE TRAVAILlEUR, 9 mai 1975.

Gravel, Claude, "Le décès du chanoine Groulx émeut tout le Canada français ", LA PRESSE, 24 mai 1967, p. 21.

Grignon, Claude- Henri, "Quand un vieillard se croit jeune ", LE JOUR NAL DES PAYS D'EN HAUT, 20 mai 1967.

- "Une page immortelle ", LE JOURNAL DES PAYS D'EN HAUT, 3 juin 1967, p. 4.

— «'historien toujours vivant ", LE JOURNAL DES PAYS D'EN HAUT, 3 juin 1972, p. 2.

Groulx, Me Yvon, «La SSJB rend un hommage public à l'un de ses membres les plus distingués ", MONTRÉAL-MATIN, 24 mai 1967.

— "La SSJB de Montréal reste confessionnelle", Propos de Me Yvon Groulx, Chemins de l'Avenir, du chanoine Lionel Groulx ", DIMANCHE-MATIN, 28 mars 1965. 
Guay, M.-A., "Asservissement ou indépendance ", LE DEVOIR, 23 juin 1964. Guèvremont, Germaine, "Des témoignages de tous les coins du Québec", LA PRESSE, 24 mai 1967; LE DEVOIR, Montréal, 24 mai 1967.

Guiho, Joseph, "Un père de la nation ", MOISSON, journal étudiant de Rouyn, juillet 1967.

— «La presse anglophone est d'accord avec le maire Jean Drapeau », LA PRESSE, 11 août 1967.

— "Charles de Gaulle, Lionel Groulx: deux hommes, un même langage ", LE QUÉBÉCOIS, vol. 1, no 1, Rouyn, octobre 1967, p. 6-8.

— «Ryan sur la sellette», éditorial, LE QUÉBÉCOIS, Rouyn, novembre 1967.

— «En des circonstances qui s'annoncent tragiques, nous n'avons plus de journaux qui soient véritablement à nous : Lionel Groulx ", LE JOUR, 19 octobre 1974, p. 9.

- «Une correspondance inédite du chanoine Groulx sur Claude Ryan», LE JOUR, 19 octobre 1974 - Réponse de Claude Ryan: "Du préjugé au mensonge, la distance est souvent courte ", LE DEVOIR, 21 octobre 1974 "De la maladie de la persécution", LE JOUR, 29 octobre 1974.

Guil, Roger, "Demande de cautionnement pour Paul Rose. Me Lemieux s'appuie sur une jurisprudence du chanoine Groulx », MONTRÉAL-MATIN, 27 avril 1972, p. 5.

Guilmette, Pierre, «Raymond Barbeau, L'Alliance laurentienne et le début du souverainisme québécois - les sources de Raymond Barbeau ", LE JOUR, 14 août 1975.

Hance, Paul, "Nos écrivains ont puisé à l'histoire", QUÉBEC-JOURNAL, 10 janvier 1965 , p. 21.

Hardy, Denis, "Un grand Thérésien nous a quitté », LE PROGRÈS, 31 mai 1967, p. 7; LA VALLE DE LA DIABLE, 9 juin 1967, p. 1 ; LA VOIX DES MILLEILES, 15 juin 1967, p. 3.

Hertel, François, "Pour qui se prend-il, ce Guy Sylvestre », PHOTO-JOURNAL, 19 mai 1965 , p. 32.

Homer, Joseph, «Il faut à tout prix enseigner l'histoire ", LA PRESSE (lettre), 25 novembre 1974.

Hould, René, "Hommage au chanoine Groulx", LE DROIT, Ottawa, 27 juin 1967 , p. 6.

Huot, Maurice, "Analyse de Chemins de l'Avenir du chanoine Lionel Groulx », LE BIEN PUBLIC, 9 avril 1965.

- «Le livre canadien écrit en français prend de l'envol ", LE DROIT, 23 octobre 1965 , p. 7.

— «M. le chanoine Lionel Groulx», LE BIEN PUBLIC, 27 janvier 1967, p. 3.

- "Le chanoine Lionel Groulx passe à l'histoire qui lui était si chère", MONTRÉAL-MATIN, 24 mai 1967.

— «Hommage à la mémoire du chanoine Groulx», LE BIEN PUBLIC, TroisRivières, 9 juin 1967.

- «En quelques mots - C'est pénible», LE BIEN PUBLIC, 30 juin 1967.

- «Le Canada français pleure de nouveau sur la tombe du chanoine Lionel Groulx - une plaque sur la maison natale", MONTRÉAL-MATIN, 27 mai 1968. 
— «Une page de feu l'abbé Groulx », LE BIEN PUBLIC, 15 novembre 1968, p. 3-5.

— "Sur un livre négligé", MONTRÉAL-MATIN, 2 janvier 1971, p. 8.

- «Suite d'un grand livre", MONTRÉAL-MATIN, 12 mai 1971, p. 8.

— «Sur deux livres», LE BIEN PUBLIC, 13-20 décembre 1974, p. 27.

Illettré (L'), [ Harry Bernard], "L'enseignement du chanoine Groulx", LE DROIT, 10 décembre 1965, p. 6.

- «Le chanoine Groulx n'a pas enseigné en vain», LE BIEN PUBLIC, 17 décembre 1965, p. 2; LA LIBERTÉ ET LE PATRIOTE, 6 janvier 1966, p. 11; LE TRAVAILLEUR, 13 janvier 1966, p. 1.

- "La grande dame de notre histoire", LA LIBERTÉ ET LE PATRIOTE, 8 décembre 1966, p. 11; LE BIEN PUBLIC, 9 déc. 1966, p. 3; LE TRAVAILLEUR, 15 décembre 1966, p. 6, 7.

- «Les nobles origines de Ville-Marie", LE BIEN PUBLIC, 3 mars 1967, p. 6.

- «L'action vivifiante de l'abbé Groulx », LE TRAVAILLEUR, 3 août 1967, p. 35; LE DROIT, août 1967.

— «Un ouvrage de base sur l'abbé Groulx », LE TRAVAILLEUR. 8 août 1968.

— «Premier tome des Mémoires de celui qui fut l'abbé Groulx", LE TRAVAILLEUR, 17 et 24 avril 1971.

— "Petits à-côtés qu'on paraît ignorer sur L'Appel de la race de Groulx », LE TRAVAILLEUR, ler-8 mai 1971.

-- "L'abbé Lionel Groulx et L'Action française de Montréal ", LE TRAVAILLEUR, 6-13 novembre 1971, p. 1, 2.

Jasmin, Amédée, "Hommage au chanoine Lionel Groulx sur Chemins de l'Avenir ", LE DEVOIR, 13 janvier 1965.

Jasmin, Claude-Guy, "Lancement des Constantes de vie du chanoine Lionel Groulx ", MONTRÉAL-MATIN, 24 mai 1967.

Jobin, Pierre, "Chanoine Lionel Groulx", LE CARABIN, 26 mars 1965, p. 4.

Johnson, Daniel, "Quelques hommages au grand historien", MONTRÉALMATIN, 24 mai 1967.

- «Johnson et Lesage unissent leurs voix pour rendre au chanoine un dernier hommage ", LE JOURNAL DE MONTRÉAL, 24 mai 1967.

- «Vendredi, jour de deuil officiel - MM. Johnson et Lesage font l'éloge du chanoine Groulx ", L'ACTION, Québec, 24 mai 1967.

— «L'hommage officiel au chanoine Lionel Groulx", LE DROIT, 6 juin 1967.

Jones, Monique, "Prêtre, poète, historien, prophète de chez nous", ESPRIT VIVANT, 26 janvier 1978.

J.L.L., "Article sur l'animateur de CJMS, M. Claude Bruchési: "le chanoine Groulx n'a jamais été un séparatiste, mais un nationaliste ", NOUVELLES ILLUSTRÉES, 1965.

Kilbourn, William, "Time to listen to voice of French Canada: Historian", TORONTO STAR, 22 novembre 1976; THE MONTREAL GAZETTE, 30 novembre 1976.

Laberge, Camille et Annette, "Un juste hommage à monseigneur Charbonneau ", LE DEVOIR, 17 déc. 1974.

Lachance, André, "La découverte du Canada - Jacques Cartier ", LE SOLEIL, 28 mai 1966 , p. 15. 
Lachance, Gérard, «Notre État français nous l'aurons », LE CHOC DES IDÉES, mai 1970.

Lacroix, Benoît, o.p., "Des témoignages de tous les coins du Québec", LA PRESSE, Montréal, 24 mai 1967.

— «Chez Fides, hier soir, hommages... du Père Lacroix », LE DEVOIR, 24 mai 1967.

— «La pauvreté de ses parents a marqué toute son existence», LA PRESSE, 27 mai 1967.

— «Voici quelques citations que R.P. Benoît Lacroix, o.p., a choisies, dans son livre Lionel Groulx ", LE PETIT JOURNAL, 28 mai 1967, p. 5.

— «Boulevard Lionel Groulx", LE DEVOIR, 23 mai 1968, p. 5.

— «Lionel Groulx par lui-même : note critique pour lire les Mémoires de Lionel Groulx (1878-1967)", LE DEVOIR, 25 janvier 1971, p. 5.

Lacroix, Paul, "À ne pas manquer: Chemins de l'avenir», L'ACTION, 8 janvier 1965 , p. 21.

- «Hommage au chanoine Lionel Groulx sur Chemins de l'avenir", LE DEVOIR, 13 janvier 1965.

Laforce, J.-Ernest, "Ainsi va la vie... parfois... au pays du Québec», LE TRAVAILLEUR, 22 juin 1967, p. 12.

Lafortune, Ambroise, ptre, "À la mémoire du chanoine Groulx», TÉLÉ-SCOUT, journal des chefs scouts, 8 juin 1967.

Lafrance-Poirier, Bella, "Petite gerbe sur un tombeau », LE DEVOIR, 3 juin 1967, p. 5 .

Lagrave, Jean-Paul de, "Un chanoine à stature de nain médiéval ", LE DEVOIR, 10 février 1978; réponse de René Cochon, "L'art terrible de l'association ", LE DEVOIR, 20 février 1978; "Aux hommes nouveaux, des horizons nouveaux ", LE DEVOIR, 24 février 1978.

Lallier, Henri, "Le chanoine Lionel Groulx "-Constantes de vie, L'ACTION, 31 mai 1968 , p. 17.

Lamarche, Gustave, c.s.v., "Le chanoine Groulx et l'idée religieuse », LE DEVOIR, 27 mai 1967; LE TRAVAILLEUR, ler juin 1967, p. 1-2; L'ACTION, 17 juin 1967, p. 4.

Lamonde, Yvan, "Lionel Groulx et la génération perdue ", LA PRESSE, 17 février 1973, p. C2.; LE DEVOIR, 24 février 1973, p. 17.

— «Lionel Groulx : du côté de la jeunesse », LA PRESSE, 11 janvier 1975, p. D4.

Lamoureux, Marcel, ptre, "Cri d'alerte d'un historien: cinq siècles vous regardent ", LA PRESSE, 4 décembre 1965 - lettre ouverte.

— «Hommages au chanoine Lionel Groulx », L'INFOR MATION NATIONALE, mars 1966.

- «Pour un monument, LE DEVOIR, 10 novembre 1967, p. 6, col. 3.

Landry, Armour, "Denis Vaugeois rend hommage à la mémoire de Lionel Groulx ", LE BIEN PUBLIC, 20, 27 mai et 3 juin 1977; L'INFOR MATION NATIONALE, juin 1977.

Langlois, Conrad, "Chanoine Lionel Groulx et les États-associés », LA PATRIE, 24-30 décembre 1964, p. 4.

Langlois, Lucien, "Une race nouvelle", MONTRÉAL-MATIN, 23 décembre 1964. 
— «L'histoire rendue captivante", MONTRÉAL-MATIN, 18 avril 1967.

— «Un grand homme, un maître ", MONTRÉAL-MATIN, 24 mai 1967, p. 6.

- (pseudonyme, Luc), "Propos du matin », MONTRÉAL-MATIN, 24 mai 1967.

— «Il est mort il y a un an ", MONTRÉAL-MATIN, 25 mai 1968 (éditorial).

Lapalme, Bertrand, "Lionel Groulx historien de notre temps", BOULE-ÀMITES, Association des étudiants en histoire de l'Université de Montréal, mars 1967.

Laplante, Germaine, "Sur un centenaire ", ÂGE D'OR HEBDO, semaine du 30 janvier au 5 février 1978, p. 5.

Laplante, Laurent, "Après tout, il s'agit seulement de nous ", L'ACTION, 28 mars 1967 , p. 4.

— «Une perte nationale", L'ACTION, Québec, 24 mai 1967, p. 4 (éditorial).

— "L'amour de son peuple", L'ACTION, LE DEVOIR, 27 mai 1967.

— «L'abbé Groulx ne rend pas justice à l'abbé Groulx », LE DEVOIR, 24 février 1973 , p. 17.

— "L'histoire c'est un choix ", LE JOUR, 5 décembre 1974.

Laplante, Rodolphe, "Un grand exemple de courage", L'INFORMATION NATIONALE, mai 1965.

Lapointe, Renaude, "Une demande irrecevable ", LA PRESSE, 16 mai 1968, p. 4.

Laporte, Pierre, "Oeuvre immense", LE PETIT JOURNAL, 3 janvier 1965, p. $24 \mathrm{~A}$.

— «Le témoignage de Pierre Laporte", LE DEVOIR, 24 mai 1967, p. 5.

Larochelle, Jean-Thomas, "Vérité d'abord", LA PRESSE, 25 avril 1964.

Laurendeau, André, “Une longue incompréhension », LE DEVOIR, 22 avril 1964, p. 4.

— «Encore le 'racisme' du chanoine Groulx ", LE DEVOIR, 24 avril 1964, p. 4.

- "Lionel Groulx vu par un ami intime", LE SOLEIL, 24 mai 1967, p. 23.

— «Lionel Groulx », LE DEVOIR, 24 mai 1967 (éditorial), p. 4 ; reproduit dans LE DROIT, 8 juin 1967, p. 6; dans Québec 67, revue du MAC, Paris, octobre 1967, p. 114-116.

Lavergne, Claude, "Canadiens français ou Québécois", DIMANCHE-MATIN (éditorial), 26 juin 1977, p. 5.

Lavoie, Arthur, "Célébrons la mémoire du chanoine Groulx », lettre au JOUR, 19 juin 1974.

Leduc, Jean-Paul, "La phraséologie des mercenaires d'Ottawa", lettre au DEVOIR, 13 janvier 1978.

Leduc, Joseph-R., "Hommages au chanoine Groulx et à M. L.-R. Desrosiers, L'ÉCHO DU NORD, 14 juin 1967, p. 60 et 62.

Lefebvre, Guy, "La nation canadienne-française a une dette de reconnaissance à l'endroit du chanoine Groulx ", LE SOLEIL, 24 mai 1967, p. 22.

Lefrançois, Guillaume, "Laisserons-nous sombrer dans l'oubli le nom de Lionel Groulx?", lettre au DEVOIR, 23 août 1969; LA PRESSE, 2 septembre 1969.

— «Impatient de voir honorer Lionel Groulx", L'ACTION, 2 septembre 1969, p. 5.

— «La mémoire du chanoine Groulx pas assez honorée », LA PRESSE, 2 septembre 1969, p. 4. 
Le Gaulois, «Les funérailles du chanoine Groulx, LE JURA LIBRE (Suisse), 31 mai 1967 , p. 8.

Léger, Jean-Marc, "Consacrer une situation ou faciliter l'évolution? - Chemins de l'avenir", LE DEVOIR, ler février 1965.

- "Lionel Groulx : un demi-siècle d'enseignement et de combat ", LE DEVOIR, 26 novembre 1965.

- «Le 20e anniversaire de la RHAF", LE DEVOIR, 17 avril 1967.

— «Lionel Groulx - le service de l'histoire, le combat pour la nation", LE DEVOIR, 24 mai 1967, p. 1 et 6.

Léger, Cardinal Paul-Émile, "Oraison funèbre du chanoine Lionel Groulx », LE DEVOIR, 26 mai 1967.

— «Le chanoine Lionel Groulx avait réveillé une génération endormie", LA TRIBUNE, 27 mai 1967, p. 1.

Léger, Pierre, «Notre jeunesse se détruit ... J'ai peur pour notre avenir » PHOTOJOURNAL, 6-13 janvier 1965, p. 4.

Lemieux, Gérard, "Le témoignage d'un ancien collaborateur - Mgr Joseph Charbonneau tel que je l'ai connu ", LE DEVOIR, 20 décembre 1974.

L., R., "Et puis après...", DIMANCHE-MATIN, 28 mai 1967, p. 11.

Lesage, Gilles, "Le chanoine Groulx : chacune des deux nations a le droit d'écrire et d'enseigner sa propre histoire ", LE DEVOIR, 3 mai 1965, p. 10.

Lesage, Jean, "Vendredi - Jour de deuil officiel. MM. Johnson et Lesage font l’éloge du chanoine Groulx ", L'ACTION, Québec, 24 mai 1967.

- «L'hommage officiel au chanoine Lionel Groulx ", LE DROIT, 6 juin 1967, p. 6. Lessonini, Guy, "Toute sa vie aura été une magnifique leçon d'ardeur et de courage tranquille ", LE NOUVEAU SAMEDI, 27 mai 1967, 2 juin 1967, p. 15.

Lévesque, Albert, "Quelques témoignages", LE DEVOIR, 29 mai 1967.

Lévesque, René, "Et puis après...", DIMANCHE-MATIN, 28 mai 1967.

- "Le drapeau, nous l'avons", LE JOURNAL DE MONTRÉAL, 22 janvier 1973.

— «Du temps de Lionel Groulx les épines dorsales se présentaient en accent circonflexe ", THE SOUTHSHORE COURIER, 29 juin 1977 ; l'INFORMATION NATIONALE, septembre 1977, p. 27.

Locat, Raymond, «Mémoires de Lionel Groulx », LE TRAVAILLEUR, 10 février 1973, p. 1, 3.

— «Histoire du Canada français" de Lionel Groulx - réédition, LE TRAVAILLEUR, mai 1976.

Major, André, "Testament du chanoine Groulx", LE PETIT JOURNAL, 17 février 1965, p. A30.

— "Un héritage clandestin", LE DEVOIR, 31 mars 1966, p. 20.

- "L'île au trésor", et le chanoine Groulx", LE DEVOIR, 17 janvier 1967, p. 8.

_- «Le testament du chanoine Groulx ", LE DEVOIR, 27 mai 1967, p. 14.

— «Télévision: Groulx, Cailloux, information", LE DEVOIR, ler juin 1967, p. 8.

— «Constantes d'une vie et d'un peuple", LE DEVOIR, 3 juin 1967, p. 15.

— «Reconnaissance littéraire», LE DEVOIR, 2 décembre 1967.

— «Un numéro spécial de L'Action Nationale sur Lionel Groulx », LE DEVOIR, 5 juin 1968, p. 10. 
Malenfant, Georges-E., "Le chanoine Groulx demeurera un signe de ralliement ", L'ACTION, 25 mai 1967, p. 8; LE NOUVELLISTE, 26 mai 1967, p. 4; LE DEVOIR, 27 mai 1967 : LES CHUTES, 31 mai 1967; LE LAURENTIEN, 31 mai 1967, p. 8; LE SAINT-LAURENT, ler juin 1967, p. 4 ; LA VOIX DE SHAWINIGAN, 7 juin 1967, p. 6.

— «La SSJB de Québec: lourd tribut de gratitude", LE DEVOIR, 27 mai 1967.

- «Le chanoine Groulx", LA VOIX DE L'EST, 29 mai 1967, p. 4.

— «Message qui donne le son d'un bon métal», LE TRAVAILLEUR, 22 juin 1967.

Marcel, Jean, "Le docteur Ferron et le chanoine Groulx, des complices", LE DEVOIR, 31 mars 1966, p. 20.

Marion, Séraphin, "René Lévesque et les Anglo-Canadiens", LE TRAVAILLEUR, 10 février 1966.

- «Être ou ne pas être", LE TRAVAILLEUR, 28 septembre 1967, p. 1, 2.

Martel, Bernard, "Une prédiction de Lionel Groulx qui est en train de se réaliser ", LE DEVOIR, 23 juin 1977, p. 5.

Martel, Réginald, "Faut-il pendre Lionel Groulx?", LA PRESSE, 28 novembre 1970, p. D3.

— «Le charme voyant de la bourgeoisie - sur le chanoine et sur les autres », LA PRESSE, 2 juin 1973.

Martin, Paul-A., c.s.c., "Des témoignages de tous les coins du Québec", LA PRESSE, 24 mai 1967.

Masse, Marcel, "Le député de Montcalm rend hommage au chanoine Groulx », LE COURRIER DE MONTCALM, 31 mai 1967, p. 4.

— «Marcel Masse rend un vibrant témoignage au chanoine Groulx », L'ÉTOILE DU NORD, 31 mai 1967, p. 3.

— «Québec 68 évoque les victoires d'hier, les forces d'aujourd'hui, les gloires de demain ", L'INFORMATION NATIONALE, juillet et août 1968.

Ménard, Guylaine, "Un historien aux pieds nus ", LE DROIT, Ottawa, 10 juin 1978 , p. 21.

Meunier, Paul, «Une magistrale mise au point », lettre au DEVOIR, 17 déc. 1974.

Minville, Esdras, "Quelques témoignages", LE DEVOIR, 24 mai 1967.

Morgan, Jean-Louis, "L'homme qui lit ", - "Notre État français nous l'aurons ", L'INFORMATION MÉDICALE ET PARAMÉDICALE, 21 novembre 1978.

Morin, Jacques-Yvan, "Allocution de Jacques-Yvan Morin", LE SOLEIL, ler juin 1977.

Morin, Marc, "Le cardinal Léger fait l'éloge du chanoine Groulx ", L'ACTION, Québec, 26 mai 1967, p. 1.

Morissette, Brigitte, "Le chanoine Groulx : 88 ans et toujours d'attaque ", LA PATRIE, semaine du 17 avril 1966, p. 61.

Morissette, Julien, "Propos à propos " - le rapport Parent - «La même sauce", MONTRÉAL-MATIN, 22 janvier 1965.

- "Le chanoine Groulx, M. Johnson et M. Laporte" - Chemins de l'avenir", MONTRÉAL-MATIN, 15 février 1965.

— «Du chanoine Groulx au 'groulxisme' ", MONTRÉAL-MATIN, ler juin 1967, p. 12. 
- «Une ouvre qu'il faut lire», MONTRÉAL-MATIN, 19 décembre 1970, p. 56.

M., R., "Les prix Lionel-Groulx ", LA PRESSE, 13 novembre 1978 - section Arts et spectacles, p. A12.

Myers, Hugh Bingham, "Canon Groulx on Confederation", THE MONTREAL STAR, 31 mai 1967, p. 12.

M.P., "Une revue de Paris rend hommage à M. le chan. L. Groulx ", LE DEVOIR, 25 août 1964.

Nadeau, Roger, "Les Chemins de l'avenir du chanoine Lionel Groulx », LE PETIT JOURNAL, 17 janvier 1965.

Neveu, Noël, "Catéchisme pour un Canadien français », MOISSON, journal étudiant de Rouyn, novembre 1967, p. 3.

Nish, Cameron, "Nish veut faire une piastre avec notre histoire", NOUVELLES ILLUSTRÉES, 5 mars 1966.

Normandin, Michel, "Maître, exemple et symbole", LE DEVOIR, 26 mai 1967.

O'Bready, Mgr Maurice, p.d., "Le chanoine Lionel Groulx", L'HEBDO DE SHERBROOKE, 31 mai 1967.

O'Hara, William, "Whose History? Plum-cake dried Biscuit », THE MONTREAL STAR, 23 janvier 1965.

Oliver, Michael, "Quelques témoignages », LE DEVOIR, Montréal, 24 mai 1967.

Olivier, Pierre, " 50 ans après un premier cours, le chanoine Groulx retourne à l'Université expliquer son enseignement ", LA PRESSE, 25 novembre 1965, p. 19.

O’Neill, Louis, «Mes rencontres avec le chanoine Groulx », LA TRIBUNE, 25 mai 1967, p. 6.

Pagé, Raymond, "La foi dans la vie », LE DYNAMIQUE, ler juin 1967, p. 4.

Pallascio-Morin, Ernest, "Lettres et sciences", LE DEVOIR, 18 juillet 1964; L'ACTION, 31 décembre 1965, p. 25.

- «Chemins de l'avenir", L’ACTION, 31 décembre 1964, p. 25.

- «Retrouver 'l'homme intégral' est une nécessité de l'heure", à propos de Chemins de l'avenir, PHOTO-JOURNAL, semaine du 4 au 10 mai 1970, p. 19.

- "Écrivains d'ici Lionel Groulx", L'INFORMATION MÉDICALE ET PARAMÉDICALE, 17 janvier 1978.

Paquette, Jacques, "Mort, où est ta victoire ", LE NOUVELLISTE, 26 mai 1967, p. 4.

Paré, René, "Le chanoine Lionel Groulx ", L'ARTISAN, juillet 1967, p. 5.

Parent, G.-E., "La fin d'une époque », LE DEVOIR, 3 juin 1967; LE DROIT, 24 juin 1967.

Parent, Zoël, «Lettres au Devoir »-Chemins de l'avenir, LE DEVOIR, 21 janvier 1965.

Patry, Pierre, "In Memoriam ", LA PRESSE, 27 mai 1967.

- «Pierre Patry raconte la dernière conversation qu'il a eue avec le chanoine Groulx ", L'ÉCHO DE VAUDREUIL-SOULANGES, 31 mai 1967, p. 3.

P., C., "Aux yeux du chanoine Groulx, les traditions nationales sont une arme puissante pour vaincre les crises en ce bas monde... ", LE NOUVELLISTE. 11 mars 1965, p. 4. 
- «Le chanoine Groulx continue sa lutte en faveur de la cause du Canada français", LA TRIBUNE, 11 mars 1965 , p. 8.

- «Le chanoine Groulx ne dételle pas en dépit de ses 87 ans ", LA VOIX DE L'EST, 13 mars 1965, p. 2; L'ÉVANGÉLINE, 9 avril 1965, p. 4.

— «Le chanoine Lionel Groulx s'éteint à l'âge de 89 ans ", LA VOIX DE L'EST, 24 mai 1967 , p. 1.

Pearson, Lester B., «Le Canada tout entier perd un éminent citoyen », L'ACTION, Québec, 25 mai 1967; LE DEVOIR, 26 mai 1967.

Pelletier, Gérard, “Une 'offensive astucieuse’? ", LA PRESSE, 20 janvier 1965, p. 4.

Pelletier, Jacques, «L'avenir du Canada français », LE SOLEIL, 30 janvier 1965, p. 32.

Pelletier, Marc, «Un grand Canadien français n'est plus», L'ÉCHO DE VAUDREUIL-SOULANGES, 24 mai 1967.

Pelletier, Michel, "Va-t-on manquer le bateau... La conscience de la nation ", LES CAHIERS DES ÉTATS GÉNÉRAUX, 25 juillet 1967, cahier 4.

- "Hommage", LE DEVOIR, 25 novembre 1967.

- «Lettres au Devoir" - Chemins de l'avenir, LE DEVOIR, 21 janvier 1965.

Pelletier, Pierre, «La socialisation, un processus urgent et nécessaire - la voix des jeunes ", L’ACTION, ler février 1965.

Pelletier, Réal, "Le ch. Groulx publie : Chemins de l'avenir », LE DEVOIR, 22 déc. 1964.

Pilote, Dr Lomer, «Le nationalisme, le nazisme... et M. Walter O'Hearn ", LE DEVOIR, 29 avril 1964.

Plourde, Suzanne, "Lettre au Devoir», LE DEVOIR, 2 mars 1978.

Poirier, Marie, "Les historiens scrutent Groulx et son temps" (congrès d'histoire de l'IHAF), MCGILL DAILY, Montréal, 17 octobre 1978, p. 3, 4.

Poisson, Roch, "Un dernier hommage au chanoine Groulx", PHOTOJOURNAL, semaine du 24 au 31 mai 1967, p. 7.

- "Cent ans... de vie", PHOTO-JOURNAL, du 4 au 11 octobre 1967, p. 65.

- «Rétrospective de l'an 1967 ", PHOTO-JOURNAL, 27 décembre 1967 au 3 janvier 1968, p. 52.

Pontaut, Alain, "Chez Fides, lancement de son dernier ouvrage ", LA PRESSE, 24 mai 1967, p. 21.

- «Le dernier message de Lionel Groulx", LA PRESSE, 27 mai 1967, p. 27.

— «Vingt ans d'érudition et de persévérance», LA PRESSE, 8 avril 1967, p. 24.

— «Groulx le libérateur », LA PRESSE, 15 juin 1968, p. 27.

- «Les borgnes et le voyant ", LE JOUR, 12 décembre 1974.

Poupart, Jean-Marie, "Lionel Groulx, fier-modeste», LE DEVOIR, 25 janvier 1975 , p. 14.

Presse Canadienne, "Le chanoine Lionel Groulx s'éteint à l'âge de 89 ans ", LA VOIX DE L'EST, 24 mai 1967, p. 1.

R., A., "Le chanoine Groulx demeurera", LA PAROLE, 31 mai 1967, p. 4.

Ricard, François, "Relire Lionel Groulx" (L'Histoire du Canada français depuis la découverte - réédition), LE DEVOIR, 6 novembre 1976, p. 18.

Richard, Jean-Pierre, "Le nationalisme entre la gauche et la droite », LA PRESSE, 7 janvier 1977. 
Richardson, Joyce, "Canadians in U.K. Whoop It Up», THE MONTREAL STAR, 15 juillet 1967 , p. 4.

Richer, Julia, "Quelques témoignages", LE DEVOIR, 24 mai 1967.

- «Mes Mémoires, tome I", L'INFORMATION MÉDICALE ET PARAMÉDICALE, ler déc. 1970.

- «Les vingt-cinq ans de la RHAF", ibid., 6 juin 1972.

R.I.N., "Quelques témoignagnes », LE DEVOIR, 24 mai 1967; LA PRESSE, 24 mai 1967.

Rioux, Albert, "René Chaloult et Lionel Groulx », LE DEVOIR, 6 janvier 1979.

Rioux, Mathias, "Fête du Québec et historien national" (éditorial), MONTRÉAL-MATIN, 25 juin 1977.

Rioux, Pierre-Paul, "Rééditer et relire l'ouvre du chanoine Groulx", LA PRESSE, 4 février 1971; L'INFORMATION NATIONALE, mars 1971, p. 4; LE DEVOIR, 25 janvier 1971, p. 6.

Rivard, Julien, "Chemins de l'avenir", MOISSON, Rouyn, mai et juin 1965.

Rivet, Jean-Paul, "Prêtre et historien: Lionel Groulx", L'OSSERVATORE ROMANO, 27 juin 1978, p. 10.

Robert, Paul-Émile, «Un grand disparu », DIALOGUE, journal de la Laurentienne, compagnie d'assurance, novembre 1967, p. 11.

Robin, Étienne, "La grande dame de notre histoire", L'INFORMATION MÉDICALE ET PARAMÉDICALE, 4 octobre 1966, p. 36.

— «Reconnaissances littéraires", ibid., 2 janvier 1968, p. 28.

— «Mes Mémoires -- 2, de Lionel Groulx ", ibid., ler juin 1971, p. 16.

Rocan, "L'imprimé », L'INFOR MATION MÉDICALE ET PARAMÉDICALE, 3 mai 1966, p. 23.

Rondeau, E., «Le chanoine Groulx n'est plus, LE COURRIER DE BERTHIER, 25 mai 1967 , p. 9.

Roussan, Jacques de, "Ici il a vécu et travaillé ", PERSPECTIVES-DIMANCHEMATIN, (reportage photographique), 8 juillet 1967.

Routhier, Benoît, "Dans 'Constantes de vie', Groulx situe la patrie des Canadiens français ", LE SOLEIL, 27 mai 1967, p. 20.

- «Si le Canadien français veut vivre, il lui faut un dénominateur commun - le chanoine Lionel Groulx ", LE SOLEIL, 16 septembre 1967, p. 18.

Roy, Denis, "Chemins de l'avenir", LA CONCORDE, 16 mars 1971, p. 2.

Roy, Louis-Philippe, «Maître chez soi "... en assurance-vie, L'ACTION, Québec, 11 juin 1964.

— «Faut-il enseigner l'histoire avec froideur et sécheresse », L'ACTION, 23 janvier 1965, p. 4.

— «Une province comme les autres", MONTRÉAL-MATIN, février 1965.

Ryan, Claude, "Une grave injustice du Star», LE DEVOIR, 20 avril 1964.

— "Le Star s'empêtre davantage", LE DEVOIR, 23 avril 1964.

- "Le dernier livre du chanoine Groulx », LE DEVOIR, 28 décembre 1964.

— «L'histoire est-elle une science comme les autres?» [rapport Parent], LE DEVOIR, 21 janvier 1965.

— «Le chanoine Groulx a 88 ans », LE DEVOIR, 13 janvier 1966.

— «Le père spirituel du Québec moderne", LE DEVOIR, 24 mai 1967, p. 4, 5. 
— «Du préjugé au mensonge, la distance est souvent courte», LE DEVOIR, 21 octobre 1974, p. 6.

- «Un jugement sommaire du chanoine Groulx sur Monseigneur Charbonneau - Être étrange ou victime des gardiens du temple?", LE DEVOIR, 10 décembre 1974, p. 7.

,Saillant, François, "Pauvre Lionel Groulx", LA PATRIE, semaine du 29 juin 1969, p. 30.

Saint-Pierre, Angéline, "Quand mieux vaut se taire ", Lettre à Claude Ryan, LE DEVOIR, 14 décembre 1974.

Salaberry, Michel de, "L'Hommage d'un jeune homme : le chanoine Groulx ", LE DROIT, 3 juin 1967.

Sauriol, Paul, «Les liens de pensée et d'action entre l'abbé Groulx et le Devoir », LE DEVOIR, 25 mai 1967, p. 5.

Savard, André, "L'oeuvre du chanoine Groulx ", lettre à LA PRESSE, 22 juin 1976.

Schneider, Pierre, "Lionel Groulx clandestin», LE NOUVEAU SAMEDI, 22 juillet 1967.

Séguin, Robert-Lionel, "Le plus grand des Canadiens français nous laisse un fantastique héritage - le chanoine Lionel Groulx", LA SEMAINE ILLUSTRÉE. 29 mai au 4 juin 1967, p. 14.

Société Saint-Jean-Baptiste de Montréal, "Des témoignages de tous les coins du Québec", LA PRESSE, 24 mai 1967.

- "La SSJB rend hommage public à l'un de ses membres les plus distingués", MONTRÉAL-MATIN, 24 mai 1967.

- «Les Canadiens français ont une immense dette de reconnaissance à son endroit ", LE JOURNAL DE MONTRÉAL, 24 mai 1967.

Stanley, George F.G., "Lionel Groulx est parfois injuste envers les anglophones, mais il n'est pas anglophobe", LA PRESSE, 30 mars 1965, p. 19.

- «Un professeur de Kingston regrette que Lionel Groulx soit méconnu des Canadiens ", LE DEVOIR, 31 mars 1965.

- «Lionel Groulx, historien : un témoignage anglo-canadien», LE DEVOIR, 26 mai 1967 , p. 6.

Sylvestre, Guy", "Nous, les neveux d'Amérique », LE DEVOIR, 31 mars 1966, p. 17.

Taaffe, Gérald, "Une histoire du Canada... ou deux?», LE JOURNAL DE MONTRÉAL, 15 février 1965, p. 15.

Tardif, Germain, "Décès du chanoine Lionel Groulx », LA PRESSE, 23 mai 1967.

Théberge, Jean-Yves, "Le testament du chanoine Groulx", LE CANADA FRANÇAIS, 28 janvier 1965, p. 20.

— «Les nouveaux livres", ibid., 23 septembre 1965, p. 24.

— «Aurait-on perdu le courage?", ibid., 24 février 1966, p. 22.

- "Merci à cet historien", ibid., 2 juin 1966, p. 42.

— «Lionel Groulx", ibid., ler juin 1967, p. 28.

— «Le dernier livre de Lionel Groulx", ibid., 13 juillet 1967, p. 30.

— «Lionel Groulx ", ibid., 8 août 1968, p. 26.

— «Les 'Mémoires' de Lionel Groulx ", ibid., 25 novembre 1970, p. 52. 
Thériault, Jacques, "La Fondation Lionel-Groulx étend son action", LE DEVOIR, 12 février 1976; L'INFORMATION NATIONALE, 25 février 1976.

Therrien, Arsène, "Le souvenir du chanoine Lionel Groulx ", lettre au DEVOIR, 4 octobre 1969 , p. 5 ; même texte intitulé : «Hâtons-nous d'honorer la mémoire du chanoine Groulx ", LA PRESSE, 24 octobre 1969, p. 4; LE PETIT JOURNAL, semaine du 23 novembre 1969, p. 10.

Toupin, Paul, "Montréal cosmopolite», LE DEVOIR, 27 octobre 1966.

Trahan, Gérard, "Groulx contre Sartre ", L'ACTION, 16 février 1965.

Tremblay, G.-A., "Du mépris pour le chanoine Groulx", lettre au JOUR, 20 février 1975.

Tremblay, Paul-Émile, notaire, "Pourquoi nous devons dire adieu à notre État français ", lettre ouverte au DEVOIR, 27 septembre 1977, p. 5 ; LA PRESSE, 3 octobre 1977.

Trudel, Clément, "Il y a 25 ans, le fleurdelisé », LE DEVOIR, 20 janvier 1973, p. 6.

— "Groulx a su montrer à son petit peuple le chemin de la fierté ", LE DEVOIR, 18 janvier 1978.

- "Campagne de souscription pour le Centre de recherche Lionel Groulx ", LE DEVOIR, 18 avril 1978, p. 12; reportage photographique dans le JOURNAL DE MONTRÉAL, 18 et 19 avril 1978.

Trudel, Jean-Paul, "Trois grands professeurs" - lettre ouverte au DEVOIR, 19 Janvier 1966.

Université de Montréal, "Des témoignages de tous les coins du Québec", LA PRESSE. LE DEVOIR, 24 mai 1967.

Vachon, J.-A., "À la mémoire de Lionel Groulx", lettre à LA PRESSE, 13 mai 1972; même texte, intitulé: "En l'honneur de l'historien Groulx ", L'ACTION, 18 mai 1972.

Vadeboncour, Pierre, "Groulx et Cité libre, - 3 février 1960, Centenaire", JOURNAL DE MONTRÉAL, 13 janvier 1978.

Vaillancourt, Alvarez, "L'abbé Lionel Groulx ", LA TRIBUNE, Sherbrooke, 25 mai 1967 , p. 6.

Valcour, Pierre, "Des explications trop faciles sur le départ de Monseigneur Charbonneau - lettre au Père Bernardin Verville", LE DEVOIR, 3 septembre 1976.

— «Le Monseigneur Charbonneau du Père Verville», LA PRESSE, 7 septembre 1976, p. A5.

- "Au sujet du documentaire 'Groulx'", LE DEVOIR (lettre), 2 mai 1978.

- «Au sujet du documentaire 'Groulx' ", lettre de Pierre Valcour au Devoir, LE DEVOIR, 3 juin 1978.

Valiquette, Bernard, «Lionel Groulx ", ÉCHOS-VEDETTES, 17 juin 1967, p. 21.

— «Constantes de vie par Lionel Groulx ", ÉCHOS-VEDETTES, 24 juin 1967, p. 21.

Valois, Marcel, «Héroïsme de trente ans de résistance ", LA PRESSE, 28 octobre 1967, p. 25.

- «Vivants portraits par René Chaloult », LA PRESSE, 8 novembre 1969, p. 41.

Vaugeois, Denis, “Ce pauvre Jean-Charles (Lionel Groulx) », LE JOUR, 28 février 1974, p. 17. 
— «Lionel Groulx, premier ministre...", LE JOUR, 2 mars 1974, p. 20.

- «Allocution de Denis Vaugeois», LE BIEN PUBLIC, 2 au 27 mai 1977; L'INFORMATION NATIONALE, juin 1977; LE DEVOIR, 4 juin 1977.

Vennat, Pierre, "Québec achèterait bientôt le Séminaire de Ste-Thérèse pour en faire un Institut. Il serait rebaptisé "Collège Lionel-Groulx ", LA PRESSE, 16 février 1967; "Le Collège Lionel-Groulx sera prêt pour l'année 19671968 ", LA PRESSE, 18 février 1967.

- "Le chanoine accepte de donner son nom", LA PRESSE, 7 mars 1967, p. 7.

Verville, Bernardin, o.f.m., "Le chanoine Groulx et l'apologie de Monseigneur Charbonneau ", LA PRESSE, 26 août 1976, p. A5 ; "Réponse au réalisateur Valcour", LA PRESSE, 8 octobre 1976.

Viau, René, "Couleur et lumière: un métro sans graffiti", - Station de Métro Lionel-Groulx, LA PRESSE, 23 septembre 1978, p. D26.

Wallot, Francine, "Lionel Groulx a profondément marqué notre société depuis 50 ans", - "Valleyfield soulignera le centenaire Lionel Groulx", LE PROGRÈS DE VALLEYFIELD, 12 avril 1978, p. 16.

Wallot, Jean-Pierre, «In Memoriam », LE PROGRÈS DE VALLEYFIELD, 31 mai 1967 , p. 25.

— «L'actualité de Lionel Groulx ", LE DEVOIR, 5 juin 1978.

Winter, Hal, "Relentless in his Beliefs " - "Canon Groulx still explosive », THE MONTREAL STAR, 23 janvier 1965, p. 4.

— «Un certain sourire», LE DROIT, Ottawa, 13 mars 1965.

\section{ARTICLES DE JOURNAUX ANONYMES}

(Vu l'anonymat et l'abondance de ces articles, nous avons cru de bonne politique d'adopter l'ordre chronologique.)

1964, Anonyme,

- "Canon Lionel Groulx - Yes, you could call me a nationalist. I' ave never been afraid of that word", THE STAR WEEKLY AND CANADIAN WEEKLY, 4 avril 1964.

- «Le chanoine Groulx : les Canadiens anglais sont plus nationalistes que nous ", LE DEVOIR, 14 avril 1964.

- Mise au point du chanoine Groulx ", LE DEVOIR, 15 avril 1964 ; L'ÉCHO DE VAUDREUIL-SOULANGES, 22 avril 1964.

- About Canon Groulx ", THE STAR, 22 avril 1964.

- «Walter O’Hearn: l'Église a été "la servante" du nationalisme au Québec", LA PRESSE, avril 1964.

— «À propos du chanoine Groulx ", LA PRESQU'ILE, PANORAMONDE, Vaudreuil, 16-22 mai 1964.

- "Le chanoine Groulx dit ce qu'il entend par "être maître chez soi ", LE DEVOIR, 8 juin 1964 , p. 3,8 .

— "Finies les génuflexions - le chanoine Groulx à la Saint-Jean-Baptiste", MONTRÉAL-MATIN, 8 juin 1964.

- "Nous devons chercher une autre conception de notre fiscalité", L'ÉVÉNEMENT, Québec, 8 juin 1964. 
- «Le temps est venu de se parler dans les yeux" (chanoine Groulx), L'ÉVÉNEMENT, Québec, 8 juin 1964.

- "Cet homme avait prévu les événements actuels 50 ans avant les autres", LE NOUVEAU-SAMEDI, 13 juin 1964.

— «Le vieux et encore vaillant patriote nous parle...", UNIR LE PEUPLE, ler août 1964: 9.

— «Le Canada français, réalité vivante" - Éditorial CJMS RADIO, Montréal, 24 juin 1964.

— «Le chanoine Lionel Groulx nous parle», L'ÉMERILLON, août 1964.

- "Conclusions d'une rencontre religieux/hommes d'affaires, L'INFORMATION NATIONALE, août-sept. 1964.

1965 - «La production littéraire en 1964 », LE CANADA FRANÇAIS, 7 janvier 1965, p. 20.

- «Après 'Notre Maître le Passé' - 'Chemins de l'avenir' ", L'INFORMATION NATIONALE, janvier 1965 (SSJB).

- «Le docteur Jutras reçu par notre historien national, le chanoine Lionel Groulx ", LA NOUVELLE, Victoriaville, 1965.

- «Un message important du chanoine Groulx concernant 'l'histoirepropagande'", LE DROIT, 19 janvier 1965.

- «Teaching History", THE MONTREAL STAR, 19 janvier 1965, p. 6.

— "Le rapport Parent inquiète le chanoine Lionel Groulx ", LE DROIT, 19 janvier 1965, p. 15.

- "Les manuels d'histoire: la thèse de M. Groulx ", - Documents - LE DEVOIR, 22 janvier 1965.

— «Nous sommes ici au pays des mythes », LA PRESSE, 28 janvier 1965, p. 27.

- "Conférence sur neuf penseurs canadiens-français: le chanoine Lionel Groulx (29 mars), à McGill, par le doyen G.F.G. Stanley, du collège militaire de Kingston ", LE DEVOIR, 28 janvier 1965.

- «Le chanoine Groulx et l'histoire: d'elle-même notre histoire fera son chemin, sa propagande", LE DEVOIR, 28 janvier 1965.

- «Canon Groulx raps Education Report », THE STAR, janvier 1965; THE GAZETTE, 18 janvier 1965.

- «Différent, le Canadien français?» rapport Parent, PANORA-MONDE, LE JOURNAL DE SHERBROOKE, 30, 1, 5 février 1965.

- «Opinion du chanoine Groulx sur les États associés », L'INFOR MATION NATIONALE, février 1965.

— «Les événements de 1965 donnent raison au chanoine Lionel Groulx », LE JOURNAL DE MONTRÉAL, 25 mars 1965.

— «Réunion annuelle de L'I.H.A.F.", LE DEVOIR, 29 avril 1965.

- «L'enseignement historique n'a pas à se faire haineux, ni désagréable chanoine Groulx ", L'ÉVANGÉLINE, 25 mai 1965, p. 4.

— "Un grand exemple de courage », L'INFORMATION NATIONALE, mai 1965 , p. 5.

- "Les rues de St-Léonard ont des noms français ", - rue Lionel-Groulx, DIMANCHE-MATIN, 13 juin 1965. 
- «Un banquet national bien réussi : sous le patronage des Fêtes du Canada français: le chanoine Lionel Groulx était parmi les invités à la table d'honneur", MONTRÉAL-MATIN, 23 juin 1965.

— «La Patente" ressuscite sous le nom de Jean Talon», allocution de Lionel Groulx, LA PRESSE, 27 septembre 1965.

— "La chambre close, un thème cher à l'écrivain canadien-français", Allusion du conférencier à certains grands écrivains, comme le chanoine Lionel Groulx ", LA PRESSE, 2 novembre 1965.

— «Lionel Groulx et l'histoire: un témoignage engagé», LE SOLEIL, 25 novembre 1965 , p. 18.

— "L'histoire centrée sur l'homme", MONTRÉAL-MATIN, 26 novembre 1965.

- "Cinquante ans au service de l'histoire", INTER, mensuel d'information des diplômés de l'Université de Montréal, nov.-déc. 1965.

- «Deux professeurs s'élèvent contre la conception que se fait la Commission Parent de l'enseignement de l'histoire ", LE DEVOIR, 21 décembre 1965.

1966 - «A Chat with Canon Lionel Groulx, 88 tomorrow; "My Work is Finished "-But Success in Sight ", THE GAZETTE, 12 janvier 1966, p. 37.

— «Mémoire sur l'enseignement de l'histoire», L'INFORMATION NATIONALE, janvier 1966.

— «Le Chanoine Groulx a 88 ans", L'INFORMATION NATIONALE, février 1966.

— «Fides au Salon du Livre», LA PRESSE, 19 mars 1966, p. 2.

- «Le chanoine Groulx a revisé un 'Jacques Cartier', paru en 1934, relancé au Salon du Livre", LE DEVOIR, 5 avril 1966, p. 3.

- «Le chanoine Lionel Groulx et les Chemins de l'avenir", LA NATION, avril 1966.

— «Fragments d'histoire», LE PETIT JOURNAL, semaine du 15 mai 1966.

— «Bientôt dans sa 90e année ", L'INFORMATION NATIONALE, décembre 1966.

1967 - «Le Québec a besoin d'un ministère de l'Ungava », LA PRESSE, 30 janvier 1967; LE DEVOIR, 31 janvier 1967.

- "Quebec: Equality or Independence - Premier Johnson's Book», THE MONTREAL STAR, 9 février 1967.

- "La Revue d'histoire de l'Amérique française fête ses vingt ans", MONTRÉAL-MATIN, 15 avril 1967; LA PATRIE, 16 avril 1967.

- «L'histoire rendue captivante», MONTRÉAL-MATIN, 18 avril 1967.

— «À qui servent les historiens sinon à se contredire? - Le chanoine Groulx ", LA PRESSE, 8 mai 1967, p. 18.

1967, 23 mai

- "Canon Lionel Groulx", THE QUEBEC CHRONICLE-TELEGRAPH.

- «Le chanoine Lionel Groulx, nationaliste, écrivain et historien, meurt à 89 ans ", L'ACTION, Québec.

- «Historien, le chanoine Groulx fut un grand patriote», LE DROIT, Ottawa. 
- «Spokesman for Quebec nationalism-Controversial Canon Groulx dies ", THE MONTREAL STAR.

1967, 24 mai

- «Lionel Groulx est mort - Jour de deuil vendredi», LE DEVOIR, p. 1 ;

LE SOLEIL, p. 1 ; L'ACTION; LA PRESSE.

- «Deuil national pour le Québec", MONTRÉAL-MATIN.

- "Quebec proclaims official mourning - Canon Groulx funeral», THE MONTREAL STAR.

- «Author, historian Canon Groulx dies - Quebec mourns Canon Groulx ", THE GAZETTE.

- «Controversial author and historian, Canon Groulx dies», THE MONTREAL STAR, p. 5.

- «Lionel Groulx - notes biographiques ", LE DEVOIR.

- «Points saillants de la vie du chanoine Groulx», L'ACTION.

- "A concept of mission: "Lionel Groulx, opinion moulder», THE MONTREAL STAR.

- «Le Canada français pleure le chanoine Groulx», LE JOURNAL DE MONTRÉAL.

- "L'historien du Canada français, le chanoine Lionel Groulx meurt terrassé par une crise cardiaque, LE JOURNAL DE MONTRÉAL.

- «Le chanoine Groulx, une grande figure du Canada français, est décédé à Vaudreuil, L'ÉCHO DE VAUDREUIL-SOULANGES.

- «French Canadian Nationalist Dies", SHERBROOKE DAILY RECORD.

- «Johnson et Lesage unissent leurs voix pour rendre au chanoine un dernier hommage ", LE JOURNAL DE MONTRÉAL; LE DEVOIR, LE SOLEIL, L'ACTION, p. 1.

— «Le chanoine Groulx décédé à 89 ans ", L'ACTION POPULAIRE, p. 1-2; LE PROGRÈS DE VALLEYFIELD.

— «PQ Nationalist Dies in Montreal», THE QUEBEC CHRONICLETELEGRAPH, p. 2.

- «Le Parlement ne siégera pas en l'honneur du chanoine Lionel Groulx ». LE JOURNAL DE MONTRÉAL.

— «Les obsèques du chanoine Lionel Groulx : jour de deuil national. Le Québec perd un de ses maîtres à penser ", LA TRIBUNE, SHERBROOKE.

- «Les Canadiens français ont une immense dette de reconnaissance à son endroit - hommage de la SSBJ ", LE JOURNAL DE MONTRÉAL, LE DEVOIR.

- «Un dernier hommage au chanoine Lionel Groulx", PHOTO-JOURNAL, 24-31 mai 1967.

- «Il tirait du destin tragique de notre peuple, une leçon d'énergie et de confiance (Jean Drapeau)", LE JOURNAL DE MONTRÉAL.

- "Quelques hommages au grand historien: Daniel Johnson, Jean Lesage, Denis Bousquet, Jean Drapeau, la SSJB», MONTREAL-MATIN.

— «Lionel Groulx vu par un ami intime", LE SOLEIL. 
— «Chez Fides, hier soir, hommages de Guy Frégault, le Père Martin, Jean Éthier-Blais, le Père Lacroix et Victor Barbeau " - "Le témoignage de Pierre Laporte", LE DEVOIR, LA PRESSE, p. 3.

— «Quelques témoignages: l'Université de Montréal, Richard Arès, S.J., Marcel Faribault, Gérard Filion, Esdras Minville, Michael Oliver, Germaine Guèvremont, les États généraux, Michel Brunet, Ramsay Cook, Julia Richer, le RIN, Robert Cliche", LE DEVOIR.

— «Des témoignages de tous les coins du Québec: Guy Frégault, Victor Barbeau, Jean Drapeau, la SSJB, l'Université de Montréal, le Père Martin, Jean Éthier-Blais, le Père Lacroix, Roger Duhamel, le RIN, Germaine Guèvremont, Marcel Trudel, Jean Bruchési, Pierre Gaxotte ", LA PRESSE.

1967,25 mai

- «Le Canada tout entier perd un éminent citoyen "(Pearson), L'ACTION.

- «L'Université de Montréal rend aujourd'hui un ultime hommage à l'abbé Groulx", LE DEVOIR, HEBDO-INFORMATION, p. 1.

- «Le chanoine Groulx demeurera un signe de ralliement ", L'ACTION, p. 8.

— «Le chanoine Groulx : un prestige sans égal», L'ÉVANGÉLINE, p. 4.

- "Canon Groulx», THE GAZETTE, p. 4.

- «Une série-choc de films de l'ONF sur l'histoire, la géographie et les hommes du Canada ", LE JOURNAL DE MONTRÉAL.

— «1935: l'abbé Groulx à Québec - 'Nos positions'», LE SOLEIL, p. 11, 15, 35.

— «Pourquoi pas le boulevard du chanoine Groulx?», LE JOURNAL DE MONTRÉAL.

— «Un ultime hommage pour le chanoine Lionel Groulx ", LE JOURNAL DE MONTRÉAL.

— «Le RIN pleure le chanoine», LE JOURNAL DE MONTRÉAL.

- "Bel hommage de M. Denis Bousquet député du comté ", LE COURRIER DE SAINT-HYACINTHE, p. $1,5$.

— «Le chanoine Lionel Groulx », LE SOLEIL, p. 4.

- "L'hommage de l'honorable Daniel Johnson au chanoine Lionel Groulx ", LE COURRIER DE SAINT-HYACINTHE, p. 1, 5.

— «Nombreux témoignages", L’ACTION, p. 8.

- «Un programme de vie ", LE SOLEIL, p. 11, 35.

1967, 26 mai

— "Obsèques d'état du chanoine Groulx", LA PRESSE; MONTRÉALMATIN.

- «Le chanoine Groulx historien, film de l'ONF au canal 2 », LA PRESSE.

- "L'Assemblée législative a ajourné ses travaux", L'ACTION.

- «Past Failures Create Great Debt», THE MONTREAL STAR, p. 6.

- "Le chanoine Groulx, notre historien national", LE BIEN PUBLIC.

- "Les bouleversements du monde ont élargi nos horizons, mais la patrie demeure et, avec elle, le devoir de nous ressaisir ", LE DEVOIR, p. 5, 7. 
1967, 27 mai

- «L'homme qui a voulu toute sa vie nous montrer à ne plus plier l'échine", LE NOUVEAU SAMEDI, 27 mai au 2 juin 1967.

- "Hommage de Sainte-Justine au chanoine Lionel Groulx"; "Serviteur inlassable du Canada français ", LE NOUVEAU SAMEDI, 27 mai au 2 juin 1967.

— «Ses propos d'actualité », LA PRESSE.

— «La SSJB de Québec: lourd tribut de gratitude", LE DEVOIR.

— «Le témoignage de Monsieur Marcel Masse", LE DEVOIR.

— «De nombreuses personnalités assistent aux funérailles du chanoine Lionel Groulx", LA PRESSE, LE JOURNAL DE MONTRÉAL.

— «La dépouille mortelle du chanoine Groulx est inhumée à Vaudreuil », LA PRESSE.

— «Dernier hommage: le chanoine Groulx avait réveillé une génération endormie ", LA TRIBUNE, Sherbrooke.

— «À quand la rue Lionel Groulx?", LE NOUVEAU SAMEDI.

- «Poet, historian gave 50 years to Quebec cause" - «Tribute - a carry flag", THE GLOBE AND MAIL.

— «Trois étapes dans la pensée politique de l'historien», LA PRESSE.

- "L'hommage de la presse du Québec au chanoine Groulx", LE DEVOIR.

— «À la télé : en vedette le chanoine Groulx", MONTRÉAL-MATIN.

- «Un film sur le chanoine Groulx inaugure une série télévisée ", LE SOLEIL, p. 33.

- «Le chanoine Lionel Groulx fera revivre l'histoire du Canada à la télévision", L'ACTION.

— "Quebec Separatists Mourn Canon Groulx», THE GAZETTE.

— «Déclaration du RIN " - "Séparatisme de l'abbé Groulx ? "- «Déclaration de Jean Lesage - Une race trahie par ses chefs?" - "Déclaration de la SSJB ", LE NOUVEAU SAMEDI.

- «M. le chanoine Lionel Groulx scrute le rapport Parent», LE DROIT.

1967, 28 mai

— «L'historien passe déjà à l'histoire - Le regretté chanoine Groulx fait la première de Canadiana, demain ", DIMANCHE-MATIN.

— «Et jusqu’à la fin de ma vie, j’aurai rêvé grand", PETIT JOURNAL, semaine du 28 mai 1967.

1967, 29 mai

— «Quelques témoignages sur le chanoine Groulx : Albert Lévesque, l'hôpital Ste-Justine, le Comité de vigilance nationale, le Club Fleur de Lys, les Chevaliers de l'Indépendance, le RIN ", LE DEVOIR, p. 5.

1967, 30 mai

— «Une série choc de l'ONF sur l'histoire et les Canadiens", LE DEVOIR.

1967, $31 \mathrm{mai}$

- "Contributions du chanoine Lionel Groulx à la Fête de Dollard des Ormeaux ", L'ACTION. 
- «Canadiana ou l'histoire qui se vit sous nos yeux"; "Le chanoine Jeannotte nous parle de son ancien maître "; "90 années consacrées au service de la nation canadienne-française", L'ÉCHO DE VAUDREUIL-SOULANGES.

— «À la mémoire du chanoine Lionel Groulx", L'ÉCHO DU NORD, p. 6.

— «Le chanoine Groulx n'est plus ... il demeurera un signe de ralliement ", LE LAC SAINT-JEAN, p. 4.

- «Le chanoine Lionel Groulx a livré sa dernière bataille", p. 2; "Le chanoine Groulx inhumé », LE PROGRÈS DE VALLEYFIELD, p. 3.

1967, juin

- «Dans la maison du Père", LE MESSAGE DES FONDATEURS DE L'ÉGLISE DU CANADA, mai-juin 1967.

- "Dernière heure - le chanoine Lionel Groulx", L'INTER-MENSUEL

D'INFOR MATION, des diplômés de l'Université de Montréal, mai-juin 1967.

— «Lionel Groulx, un maître", L'INFORMATION NATIONALE, p. 67.

- «Le chanoine Groulx et le rapport Parent", PLEIN JOUR.

1967 , ler juin

- «Hommage au chanoine Lionel Groulx", LE JOURNAL D'OUTREMONT, p. 7.

- "L'action vivifiante de l'abbé Groulx", LE COURRIER DE SAINTHYACINTHE, p. 4.

— "Le chanoine Lionel Groulx passe à l'histoire qui lui était si chère... ", LE BULLETIN DE BUCKINGHAM, p. 7 ; LA VALLÉE DE LA PETITE NATION, p. 6.

- «Le chanoine Groulx n'est plus mais il demeure, LE CLAIRON, p. 6.

- «Le décès du chanoine Groulx a ému tout le Canada français, LA LIBERTÉ ET LE PATRIOTE, p. 4.

- "Le chanoine Groulx demeurera un signe de ralliement, MONT-JOLI NOUVELLES, p. 6 ; LE PROGRÈS DU GOLFE, p. 5.

1967, 2 juin

- «Jean Marchand Gets The Needle From French-Canadian Press, THE GAZETTE, p. 7.

- «Hommage au plus vrai et au plus grand de nos maîtres - Le chanoine Lionel GroulX », PLEIN JOUR.

1967, 2 juin

- «En potinant», LE BIEN PUBLIC, p. 8.

1967, 5-30 juin

- "Le testament du chanoine Groulx (extraits de ses oeuvres)", LA SEMAINE ILLUSTRÉE, 5-11 juin 1967, p. 54.

— «En hommage au regretté chanoine Groulx », LE RÉVEIL, 7 juin 1967, p. 9.

- «Le bras droit du regretté chanoine Groulx: Mme Juliette Rémillard",

L'ÉCHO DE VAUDREUIL-SOULANGES, 7 juin 1967.

— «Constantes de vie», LE BIEN PUBLIC, 9 juin 1967, p. 2. 
- «À la mémoire du chanoine Lionel Groulx ", LA VOIX DES MILLEILES, 15 juin 1967, p. 3.

— «Un grand Québécois disparu... », L'INDÉPENDANCE, 16-30 juin 1967, p. 8 .

— «Le chanoine y allait à la classe ", LE PETIT JOURNAL, 18 juin 1967.

- "Char allégorique au défilé de la Saint-Jean ", MONTRÉAL-MATIN, 20 juin 1967.

— «En ce samedi 24 juin », BULLETIN DE BUCKINGHAM, 22 juin 1967.

- «Le chanoine Groulx nous parle», LE NOUVELLISTE, Trois-Rivières, 23 juin 1967.

- "L'hommage officiel au chanoine Lionel Groulx à l'Assemblée législative du Québec ", LE DROIT, 26 juin 1967.

- "L'ouvre écrite de Groulx", LE DEVOIR, 26 juin 1967.

- «Hommage", LA NATION FRANÇAISE, 29 juin 1967, p. 3.

1967, juillet

- «Pour la jeunesse, le Québec est un pays à gagner!», L'INDÉPENDANCE, $1-15$ juillet 1967 , p. 2, 3 .

— «Lire au soleil, quelques titres", LE DEVOIR, 29 juillet 1967.

- "Un vœu: monument à la mémoire du chanoine Lionel Groulx", LE CANADA FRANÇAIS, 6 juillet 1967, p. 40.

1967, août

- «Dans son testament le chanoine Groulx exprime un certain regret de n'avoir pu exercer de ministère ", LA PRESSE, 10 août 1967.

— «Sa pensée demeure " - "Extrait du testament du chanoine Groulx » "Citation de Marcel Masse ", L'INFOR MATION NATIONALE, aoûtseptembre 1967.

1967, septembre

- «Grande est la besogne, courte est la journée - extrait d'un testament après une journée bien remplie ", SEMAINIER PAROISSIAL, Paroisse St-Maxime, Chomedey, 3 septembre 1967.

— "Un comité-hommage à Lionel Groulx" - «Un monument à un très grand homme du Québec", L'ÉCHO DE VAUDREUIL-SOULANGES, 27 septembre 1967; PHOTO-JOURNAL, semaine du 20 au 27 septembre 1967; DIMANCHE-MATIN, 24 septembre 1967.

1967, octobre

- «Un comité projette l'érection d'un monument à la gloire du chanoine Lionel Groulx ", LA PRESSE, 2 octobre 1967.

— «Sa revue continue...", PHOTO-JOURNAL, semaine du 4 au 11 octobre 1967.

— «Cent ans de vie ", PHOTO-JOURNAL, semaine du 4 au 11 octobre 1967.

1967, novembre

- «Les Monts Groulx: un massif des Laurentides portera le nom du chanoine Groulx ", LA GAZETTE OFFICIELLE DE QUÉBEC, 18 novembre 1967; LA PRESSE, 17 novembre 1967; DIMANCHEMATIN, 19 novembre 1967; LE DEVOIR, 18 novembre 1967. 
1967, décembre

— «Timbres historiques de la SSJB», LA PATRIE, 3 décembre 1967, p. 43.

- «Le bilan des disparus", LA SEMAINE ILLUSTRÉE, 25 au 31 décembre 1967.

1968 - «Le chanoine Groulx pensait que Claude Ryan est un superficiel», L'INDÉPENDANCE, 15-31 janvier 1968, p. 3.

- «Hommage -- Que la rue Sherbrooke devienne le boulevard LionelGroulx »«, LE DEVOIR, 11 avril 1968; LE JOURNAL DE MONTRÉAL, 17 avril 1968; THE MONITOR, Montréal, 17 avril 1968; LA PRESSE, 2 mai 1968; LE DEVOIR, 18 mai 1968; LE JOURNAL DE MONTRÉAL, 16 et 18 mai 1968; LE JOURNAL DE MONTRÉAL, le 17 mai 1968; MONTRÉAL-MATIN, 18 mai 1968; LE DROIT, 15 mai 1968; LA PRESSE, 11 mai 1968.

- «Paul Manta opposé au changement du nom », LA PRESSE, 2 mai 1968.

— «Vaudreuil se souvient du chanoine Groulx, MONTRÉAL-MATIN, 3 mai 1968.

- «La SSJB commémorera l'anniversaire du décès du chanoine Lionel Groulx », LA PRESSE, 11 mai 1968, p. 67.

- "Guy Frégault évoque une sombre 'prédiction' de Lionel Groulx», LA PRESSE, 15 mai 1968, p. 141.

- «Premier anniversaire de la mort du chanoine Lionel Groulx, célébré à Vaudreuil, le 26 mai 1968 ", DIMANCHE-MATIN, 19 mai 1968; LE TRAVAILLEUR, 29 mai 1968.

— «Le Fleurdelisé ", L'ÉCHO DE VAUDREUIL-SOULANGES, 22 mai 1968.

- «Premier anniversaire de la mort de Lionel Groulx, LE DEVOIR, 23 mai 1968, p. 9.

- «Hommage à Lionel Groulx", LE SOLEIL, 23 mai 1968, p. 20.

- «Hommage posthume», MONTRÉAL-MATIN; LE DEVOIR, 25 mai 1968.

- «Canon Groulx commemorated», THE GAZETTE, 27 mai 1968.

- «La Société Saint-Jean-Baptiste rend hommage au chanoine Lionel Groulx ", L'ÉCHO DE VAUDREUIL-SOULANGES, 29 mai 1968.

— «Hommage au chanoine Lionel Groulx», L'ACTION, 29 mai 1968, p. 4.

- «Un an après sa mort le chanoine Lionel Groulx demeure plus vivant que jamais ", L'INFORMATION NATIONALE, mai 1968, p. 1, 3, 5.

- «Lionel Groulx, le maitre de prose, vu par Victor Barbeau, Jean Tétreau, Jean Éthier-Blais et Jean Marcel ", LE DEVOIR, 8 juin 1968, p. 13.

— "Groulx le libérateur " - à propos de Lionel Groulx, prêtre, no spécial de L'Action Nationale, La Semaine littéraire, LA PRESSE, 15 juin 1968.

— «Lionel Groulx ", COURRIER DU SUD, 19 juin 1968, p. 3.

— "Nous avons raison d'être fiers", LE PETIT JOURNAL, semaine du 30 juin 1968.

— «Disparus à un an d’intervalle (Groulx et Laurendeau)", L'INFORMATION NATIONALE, juillet-août 1968. 
— «La Fédération des SSJB crée un prix Lionel-Groulx», LA PRESSE, 23 août 1968; DIMANCHE-MATIN, 25 août 1968.

1969 - "Même après sa mort le chanoine Lionel Groulx continue à inspirer les chefs de file du Québec", L'INFORMATION NATIONALE, mars 1969.

— «Un sentiment qui vient de loin», LE DEVOIR, 7 mars 1969, p. 4.

- "Deuxième anniversaire de la mort du chanoine", LE DEVOIR, 23 mai 1969 ; L'ÉCHO DE VAUDREUIL-SOULANGES, 5 juin 1969.

- «Une fondation et un institut pour établir définitivement l'oeuvre politique du chanoine Groulx ", L'INFORMATION NATIONALE, juillet-août 1969.

- «Soutane de Lionel Groulx au musée de Laure Conan », LE CONFIDENT DE LA RIVE NORD INCOR PORÉE, La Malbaie, 17 septembre 1969.

1970 - «Le Québec se souvient-il de son maître?", L'INFOR MATION NATIONALE, février-mars 1970, p. 2.

- «Le 23 mai marquera le troisième anniversaire de la mort du Chanoine Lionel Groulx ", L'INFOR MATION NATIONALE, avril-mai 1970, p. 11.

- «Retrouver 'l'homme intégral' est une nécessité de l'heure», PHOTOJOURNAL, 4-10 mai 1970, p. 19.

- «La SSJB se souvient", L'ÉTOILE DE L'OUTAOUAIS - ST- LAURENT, 3 juin 1970.

- «Allocution prononcée sur la tombe du Chanoine Lionel Groulx", L'UNISSON, juin 1970, p. 5-7.

- «Le centre d'apprentissage du campus de la Cité des Jeunes de Vaudreuil portera le nom de Pavillon Lionel-Groulx", L'ÉCHO DE VAUDREUIL-SOULANGES, 2 juillet 1970.

— "Avec l'espoir de continuer ce pourquoi j'ai vécu...", LE DEVOIR, 24 octobre 1970.

— «Un cheminement vers la conscience», LE SOLEIL, 24 octobre 1970, p. 46.

- "Dans ses Mémoires, le chanoine Groulx a tenu à dire toute la vérité ", DIMANCHE-MATIN, 25 octobre 1970, p. 69.

— "Les Mémoires, tome 1", LE BIEN PUBLIC, 28 octobre 1970; LA PAROLE, 9 décembre 1970; L'INFORMATION NATIONALE, décembre 1970.

— «Un nationalisme qui n’a pas recours à la bombe", DIMANCHEMATIN, ler novembre 1970, p. 64.

1971 - «Mes Mémoires», L'INFORMATION NATIONALE, mai 1971, p. 8.

— «Succès de librairie pour les Mémoires de Lionel Groulx », LE DEVOIR, 22 mai 1971 , p. 13.

1972 - "Cinq ans après sa mort le chanoine Lionel Groulx demeure plus vivant que jamais ", L'INFOR MATION NATIONALE, mars-avril 1972, p. 13.

— «200 Québécois se souviennent... à Vaudreuil, 21 mai 1972 », L'INFORMATION NATIONALE, mars-avril 1972. 
- «Le rêve du chanoine Groulx n'est pas encore réalisé ", LA PATRIE, semaine du 18 au 24 mai 1972, p. 7.

— «À la mémoire de Lionel Groulx », LE DEVOIR, 20 mai 1972.

— «Il y a cinq ans, le chanoine Groulx mourait », L'ACTION, 20 mai 1972.

— «Notre État français nous l'aurons", L'INFORMATION NATIONALE, juillet-août 1972.

1973 - «Commémoration du 6e anniversaire de la mort du chanoine Lionel Groulx », L'ÉCHO DE VAUDREUIL-SOULANGES, 23 mai 1973, p. 21 ; LE DEVOIR, 28 mai 1973, p. 6.

- «Le chanoine Lionel Groulx à la bibliothèque Lénine", MONTRÉALMATIN, 19 juillet 1973.

- "Hommage au plus ardent propagandiste du drapeau du Québec", L'INFOR MATION NATIONALE, septembre-octobre 1973, p. 2.

1974 - "Les Mémoires du Chanoine Groulx au grand complet », DIMANCHEMATIN, 29 septembre 1974, p. 43.

- «L'auto-littérature, sur une femme au courage d'homme", LE DEVOIR, 16 novembre 1974.

- «Un témoignage du chanoine Groulx - la déposition de Mgr Joseph Charbonneau ", LE DEVOIR, 7 décembre, 9 décembre, 10 décembre 1974.

- "Mes Mémoires", tome 4, LE TRAVAILlEUR, 11 janvier 1975.

1976 - «Concours d'histoire aux étudiants des Universités et des Cegeps», LE JOURNAL DE MONTRÉAL, 12 février 1976; MONTRÉAL- MATIN, 13 février 1976; COURRIER DE LAVAL, 18 février 1976; LA PRESSE, 23 février 1976.

- «Hommage - Station de Métro», LA PRESSE, 27 février 1976.

- «Hommage du mouvement réformiste social », LE DEVOIR, 26 juin 1976; LE JOURNAL DE MONTRÉAL, 5 juillet 1976.

1977 - «Trois salons de la maison Ludger Duvernay perpétueront le souvenir des Viger, David, Groulx ", L'INFORMATION NATIONALE, janvier et février 1977.

— «Rétrospective de nos grandes batailles linguistiques, LA PRESSE, 4 avril 1977.

- "Comité de coordination des Fêtes du centenaire de Lionel Groulx (formation), DIMANCHE-MATIN, 22 mai 1977; formation des «Amis de Lionel Groulx» (comité).

— «On prépare le centenaire de l'abbé Groulx", - "À la mémoire du chanoine Lionel Groulx ", DIMANCHE-MATIN, 22 mai 1977; LA PRESSE, 24 mai 1977.

— «Station de Métro Lionel-Groulx", MONTREAL STAR, 11 juin 1977.

- «Manifestation d'hommage au chanoine Lionel Groulx (Allocution du Docteur Jacques Genest), LE JOURNAL DE MONTRÉAL, 24 juin 1977; THE MONTREAL STAR, 25 juin 1977.

- «Plaque commémorative à 261 avenue Bloomfield, inaugurée par l'honorable René Lévesque, le 24 juin 1977 ", LE SOLEIL, 18 juin 1977; LA PRESSE, 22 juin 1977, 23 juin 1977; CALGARY HERALD, juin 1977. 
1978 - «Hommage à Lionel Groulx le 16 janvier 1978 à la Bibliothèque nationale du Québec à Montréal, (table ronde, avant-première du film «Homme de croyance", lancement de "Hommage à Lionel Groulx" sous la direction de Maurice Filion, exposition Lionel Groulx ", DIMANCHEMATIN, 8 janvier 1978.

— «Le Québec rendra hommage au chanoine Lionel Groulx », LE DEVOIR, 9 janvier 1978.

— «Mon cher chanoine, c'est à ton tour...", MONTRÉAL-MATIN, 12 janvier 1978.

— «Groulx 1878 - 1978 », LE JOUR, 13 janvier 1978.

- «Le chanoine Lionel Groulx fera beaucoup parler de lui demain soir", DIMANCHE-MATIN, 15 janvier 1978.

- «Soirée du 16 janvier 1978 ", LE SOLEIL, 16 janvier 1978.

- «Notre État français nous l'aurons, le chanoine Lionel Groulx l'avait prédit pour 1980 ", LE JOURNAL DE QUÉBEC, 23 janvier 1978.

— «Lionel Groulx croyait en la souveraineté du Québec », LE DEVOIR, 23 janvier 1978 .

— «300 gathers to honour nationalism», THE GAZETTE, 23 janvier 1978.

- «Il y a cent ans naissait Lionel Groulx», ESPRIT VIVANT, 26 janvier 1978.

- «Hommage à Lionel Groulx », PLEIN JOUR, déc. 1977, janvier et février 1978.

— «Le Québec se souvient du chanoine Lionel Groulx », L'INFORMATION NATIONALE, février 1978, p. 10.

- «Motion du député Fabien Roy, à l'Assemblée nationale, pour commémorer unanimement le 100e anniversaire de Lionel Groulx ", JOURNAL DES DÉBATS, 22 février 1978.

- «Lancement du concours national Lionel-Groulx», le 27 janvier 1978,LE TRAVAILLEUR, Worcester, Mass., février 1978; L'ÉTOILE, 16 février 1978; LE COURRIER DU SUD, ler mars 1978, p. A7.

— «Lionel Groulx, prêtre - écrivain - historien", LE PROGRÈS DE VALLEYFIELD, 12 avril 1978, p. 16.

- "Lionel Groulx, homme de combat, nos questions et ses réponses", LE PROGRÈS DE VALLEYFIELD, 26 avril 1978.

- «Campagne de souscription pour le centre de recherche en histoire de l'Amérique française ", L'INFORMATION NATIONALE, mai 1978.

- «Une exposition à trois volets au centre culturel de St-Lambert", LE COURRIER DU SUD, 10 mai 1978, p. B11.

- «Henri Bourassa contre Lionel Groulx: Mais où est donc le Canada français? L'illusion débusquée ", LE NOUVEAU SUD, juin 1978.

- «Le recteur Lacoste rend hommage à Lionel Groulx », FORUM, journal de l'Université de Montréal, 23 octobre 1978, p. 5.

- «Des prix aux étudiants et une nouvelle méthode d'enseignement de l'histoire", LA PRESSE, 4 novembre 1978.

— «Groulx - la Perfide Albion sous une soutane », P.O.N.A., Snowdon, s.d. 


\section{FILMS}

1967 - Série Canadiana, film de l'ONF (Pierre Patry), 29 et 30 mai 1967. Film réalisé en 1960.

1977 - Radio-Québec, film : "Le chanoine Lionel Groulx, in memoriam », 21 juin 1977, à 21:00 heures. - 1 heure. Émission "Visages". Reprise le 18 janvier 1978.

1978 - «Sous le chêne de Mambré ": «Lionel Groulx, l'homme de croyance », à Radio-Canada, 29 janvier, à 11:00 heures - 1 heure. Présenté en primeur à la BN, 16 janvier 1978.

-Émission "Les beaux dimanches ", film documentaire sur Lionel Groulx, de Ciné-Mundo, à 20h30, 1 heure. ( 5 février). Reprise, à Québec, 16 avril 1978.

_Émission "Regards sur le monde ", avec Claude Lapointe, 19 février 1978 : "Chanoine Lionel Groulx ", 30 minutes.

\section{CONFÉRENCES ET ALLOCUTIONS}

1964 - Laporte, Pierre, Allocution au lancement de Chemins de l'avenir, 21 décembre 1964.

1967 - Angers, François-Albert, "Un témoignage ", conférence prononcée au Musée de Vaudreuil, le 12 novembre 1967, sous les auspices de la Société Historique de Montréal. 8 p.

- Brunet, Michel, Éloge du chanoine Lionel Groulx prononcé au Hall d'honneur de l'Université de Montréal, le 25 mai 1967 ", CHR, 48, 3 (sept. 1967) : 299-305.

- Filion, Maurice, homélie à la messe pour Lionel Groulx, au Séminaire de Sainte-Thérèse de Blainville, 2 juin 1967.

- Léger, Cardinal Paul-Émile, Oraison funèbre, le 26 mai 1967. Votre Église, 10 (9 juin 1967): 2-4.

1968 - Campeau, Lucien, S.J., Sermon prononcé à Vaudreuil, au premier anniversaire de la mort de Lionel Groulx, le 26 mai 1968, RHAF, 28,2 (sept. 1968) : 166-167.

- Fortin, Georges-Henri, Allocution prononcée le 26 mai 1968, à l'occasion de la cérémonie marquant le premier anniversaire du décès du chanoine Lionel Groulx, à Vaudreuil, 8 p. Reproduit dans LE DROIT, Ottawa, 30 mai 1968; reproduit dans L'INFORMATION NATIONALE, juilletaoût 1968.

1969 - Frégault, Guy, Allocution au congrès de l'IHAF, «Lionel Groulx, témoin de la fidélité et de l'objectivité vivante en histoire", mai 1969.

— Groulx, Me Yvon, Gérard Péladeau, Jean-J. Savage. Allocutions sur la tombe de Lionel Groulx, à Vaudreuil, mai 1969.

1970-Castonguay, Yvon, Léo Cazelais, l'abbé Lucien Léger, Georges-Étienne Sauvé, Aimé Vincent. Allocutions prononcées sur la tombe du chanoine 
Lionel Groulx, le 31 mai 1970: L'UNISSON, Valleyfield, juin 1970.

1971 - Éthier-Blais, Jean, "Lionel Groulx »-Discours de réception à l'Académie canadienne-française : "Ce coeur puissant a assumé l'amour d'un peuple vaincu ", LE DEVOIR, 11 déc. 1971, p. 18.

1972 - Angers, François-Albert, Richard Arès. Allocutions prononcées à l'église de Vaudreuil, au 5e anniversaire de la mort de Lionel Groulx.

- Dumont, Fernand, "Souvenir et présence de Lionel Groulx" - allocution en l'église Notre-Dame-des-Victoires, Québec, lors de la messe célébrée à l'occasion du cinquième anniversaire de la mort de Lionel Groulx ». LE DEVOIR, 25 mai 1972: 5.

1973 - Groulx, Yvon, notaire, "Hommage au chanoine Lionel Groulx, à Vaudreuil, lors du 6e anniversaire de la mort du chanoine, le 27 mai 1973 ». Texte paru dans L'INFORMATION NATIONALE, septembreoctobre 1973.

- Lacroix, Benoît, "Homélie au sixième anniversaire de la mort du chanoine Lionel Groulx ", le 27 mai 1973 à l'église de Vaudreuil.

1974 - Sherrin, Phyllis M., "Catholicism and Lionel Groulx", conférence à la Société historique du Canada, 6 juin 1974.

1977 - Genest, Dr Jacques, Lévesque, René, Allocutions prononcées lors de l'apposition de la plaque commémorative à 261 avenue Bloomfield, Outremont, le 24 mai 1977.

- Morin, Jacques-Yvan, homélie à l'église Notre-Dame-des-Victoires, à Québec, le 31 mai 1977, à l'occasion du 10e anniversaire de la mort de Lionel Groulx.

- Vaugeois, Denis, allocution sur la tombe de Lionel Groulx, à Vaudreuil, au 10 e anniversaire de sa mort.

1978 - Angers, François-Albert, «Dans quelle mesure Lionel Groulx a-t-il influencé son milieu?, au collège de Valleyfield, les 2, 3 et 4 mai 1978.

- Angrignon, Pierre, "Le premier manuel d'histoire du Canada de Lionel Groulx ", au congrès de la SHEC, à Valleyfield, les 20 et 21 octobre 1978.

- Brunet, Michel, Fernand Dumont, Hélène Pelletier-Baillargeon et Pierre Savard, table ronde sur "Lionel Groulx et la société québécoise", à la Bibliothèque nationale, le 16 janvier 1978.

- Campeau, Lucien, "Lionel Groulx, l'homme enraciné à son milieu ", à la Société historique de Montréal, le 27 février 1978. Paru dans Critères, no 22 (été 1978) : 235-246.

- Choquette, Robert, René Dionne, Jean-Pierre Gaboury, table ronde sur "Lionel Groulx et les Franco-Ontariens ", à l'Institut canadien-français d'Ottawa, le 12 mars 1978.

- Dionne, René, "L'APPEL DE LA RACE est-il un roman raciste?, au Congrès de l'IHAF, le 14 octobre 1978.

- Giguère, Georges-Émile, "Lionel Groulx, son mythe et ses mythes ", à Manchester, devant la Société historique franco-américaine, le 26 novembre 1978 . 
- Guiho, Joseph, "La vie spirituelle de Groulx ", au congrès de la SHEC, à Valleyfield, les 20 et 21 octobre 1978.

- Hathorn, Ramon «Pour une réévaluation de l'APPEL DE LA RACE ", au Congrès de l'IHAF, le 14 octobre 1978.

- Lacroix, Benoit, Armand Maltais et Jean-Pierre Wallot, Allocutions prononcées sur la tombe de Lionel Groulx le 28 mai 1978.

- Lacroix, Benoît, o.p., "Lionel Groulx, cet inconnu", - conférence inaugurale au Congrès de l'IHAF, le 12 octobre 1978.

- Mann-Trofimenkoff, Susan, "Quel modèle de société Lionel Groulx a-t-il proposé à ses concitoyens? ", au Collège de Valleyfield, les 2, 3, et 4 mai 1978.

- Mann-Trofimenkoff, Susan, "Les femmes dans l'oeuvre de Groulx », au Congrès de l'IHAF, le 13 octobre 1978.

- Perin, Roberto, "Monseigneur Bourget, précurseur de Groulx ", au Congrès de l'IHAF, le 13 octobre 1978.

- Rémillard, Juliette, causerie sur "Lionel Groulx", au Collège LionelGroulx, à Sainte-Thérèse, le 26 avril 1978; à la Bibliothèque Émile Nelligan, à Ville de Laval, mai 1978.

- Robert, Lucie, "Camille Roy et Lionel Groulx : la querelle de l'APPEL DE LA RACE ", au Congrès de l'IHAF, le 14 octobre 1978.

- Roy, Jean-Louis, "Groulx et la conscience de la nation ", au Congrès de l'IHAF, le 14 octobre 1978.

- Savard, Pierre, "Les débuts du scoutisme catholique canadien-français (1925-1935) ", présenté au Congrès de l'IHAF, les 12-13-14 octobre 1978.

- Tousignant, Pierre, «Groulx et l'histoire - interrogation sur le passé en vue d'une direction d'avenir ", à la séance de clôture du Congrès de la Fédération des Sociétés d'histoire du Québec, à Ville de Laval, les 21-2223 avril 1978.

-Wallot, Jean-Pierre, "La place de Lionel Groulx dans l'historiographie " - colloque sur «Lionel Groulx, homme de combat. Nos questions et ses réponses ", au Collège de Valleyfield, les 2, 3 et 4 mai 1978.

\section{ABRÉviations}

CHR Canadian Historical Review

IHAF Institut d'histoire de l'Amérique française

MAC Ministères des Affaires culturelles

PUL Presses de l'Université Laval

PUQ Presses de l'Université du Québec

RHAF Revue d'histoire de l'Amérique française

RUO Revue de l'Université d'Ottawa 